\section{SANDIA REPORT}

SAND97-0054 • UC-903

Unlimited Release

Printed January 1997
W.

FEB 211097

\title{
An Electromagnetic Induction Method for Underground Target Detection and Characterization
}

\author{
L.C. Bartel, D.H. Cress
}

Prepared by

Sandia National Laboratories

Albuquerque, NewWexico 87185 and Livermore, California 94550

for the United States Department of Energy

under Contract DE-AC04-94AL85000

Approved for publichelease, distow $10 \mathrm{H}$ is unlimited

\section{OSTI}


Issued by Sandia National Laboratories, operated for the United States Department of Energy by Sandia Corporation.

NOTICE: This report was prepared as an account of work sponsored by an agency of the United States Government. Neither the United States Government nor any agency thereof, nor any of their employees, nor any of their contractors, subcontractors, or their employees, makes any warranty, express or implied, or assumes any legal liability or responsibility for the accuracy, completeness, or usefulness of any information, apparatus, product, or process disclosed, or represents that its use would not infringe privately owned rights. Reference herein to any specific commercial product, process, or service by trade name, trademark, manufacturer, or otherwise, does not necessarily constitute or imply its endorsement, recommendation, or favoring by the United States Government, any agency thereof, or any of their contractors or subcontractors. The views and opinions expressed herein do not necessarily state or reflect those of the United States Government, any agency thereof, or any of their contractors.

Printed in the United States of America. This report has been reproduced directly from the best available copy.

Available to DOE and DOE contractors from

Office of Scientific and Technical Information

P.O. Box 62

Oak Ridge, TN 37831

Prices available from (615) 576-8401, FTS 626-8401

Available to the public from

National Technical Information Service

U.S. Department of Commerce

5285 Port Royal Rd

Springfield, VA 22161

NTIS price codes

Printed copy: A03

Microfiche copy: A01 
SAND97-0054

Unlimited Release

Printed January 1997
Distribution

Categegory UC-903

\title{
AN ELECTROMAGNETIC INDUCTION METHOD FOR UNDERGROUND TARGET DETECTION AND CHARACTERIZATION
}

\author{
L. C. Bartel \\ Geophysical Technology Department \\ D. H. Cress \\ Electrical Engineering Department \\ Sandia National Laboratories \\ Albuquerque, NM 87185-0705
}

\begin{abstract}
An improved capability for subsurface structure detection is needed to support military and non-proliferation requirements for inspection and for surveillance of activities of threatening nations. As part of the DOE/NN-20 program to apply geophysical methods to detect and characterize underground facilities, Sandia National Laboratories (SNL) initiated an electromagnetic induction (EMI) project to evaluate low frequency electromagnetic (EM) techniques for subsurface structure detection. Low frequency, in this case, extended from kilohertz to hundreds of kilohertz. An EMI survey procedure had already been developed for borehole imaging of coal seams and had successfully been applied in a surface mode to detect a drug smuggling tunnel. The SNL project has focused on building upon the success of that procedure and applying it to surface and low altitude airborne platforms. Part of SNL's work has focused on improving that technology through improved hardware and data processing. The improved hardware development has been performed utilizing Laboratory Directed Research and Development (LDRD) funding. In addition, SNL's effort focused on: (1) improvements in modeling of the basic geophysics of the illuminating electromagnetic field and its coupling to the underground target (partially funded using LDRD funds) and (2) development of techniques for phase-based and multi-frequency processing and spatial processing to support subsurface target detection and characterization. The products of this project are: (1) an evaluation of an improved EM gradiometer, (2) an improved gradiometer concept for possible future development, (3) an improved modeling capability, (4) demonstration of an EM wave migration method for target recognition, and a demonstration that the technology is capable of detecting targets to depths exceeding 25 meters.
\end{abstract}




\section{DISCLAIMER}

Portions of this document may be illegible in electronic image products. Images are produced from the best available original document. 


\section{ACKNOWLEDGMENTS}

The authors wish to thank E. E. Jones, D. L. Faucett, R. D. Jacobson, P. J. Gronewald, and P. M. Drozda for their support in the data acquisition and D. L. Alumbaugh for modeling support of GEM-2 data. In addition, the authors want to especially thank A. C. Cogbill for access to the GEM-2 data, I. J. Won for discussions about the GEM-2 system, and G. A. Newman for modeling discussions. Finally, the authors wish to thank members of the RTR team headed by L. G. Stolarczyk.

This work was supported by the United States Department of Energy under Contract DE-AC04-94AL85000. Sandia is a multiprogram laboratory operated by Sandia Corporation, a Lockheed Martin Company, for the United States Department of Energy. 


\section{CONTENTS}

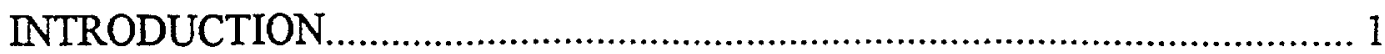

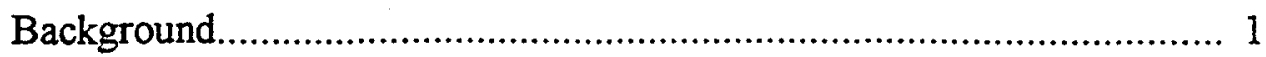

Objectives and Scope ........................................................................ 2

ELECTROMAGNETIC GRADIOMETER …............................................ 3

Performance Goal....................................................................... 3

Problem Description................................................................................ 3

EM Gradiometer Concept..................................................................... 4

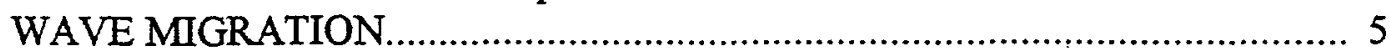

FIELD TESTS

Purpose

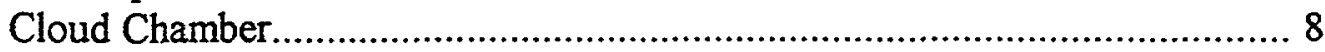

Model Calculation Results............................................................... 8

Field Survey Design......................................................................... 10

Data Collection.............................................................................. 10

Survey and Migration Results................................................................ 11

Summary of Cloud Chamber Results..................................................... 13

Yucca Mountain Tunnel.......................................................................... 14

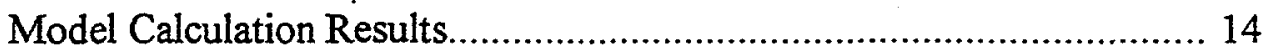

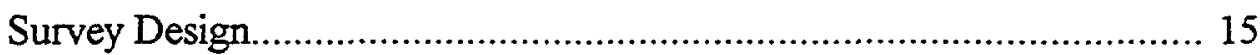

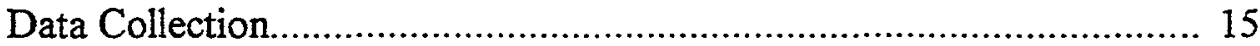

Survey and Migration Results............................................................. 15

Summary of the Yucca Mountain Tunnel Results................................... 18

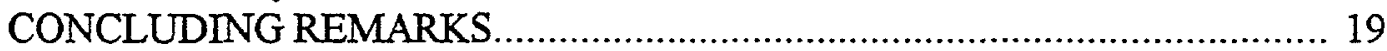

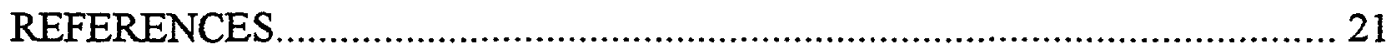

Figures

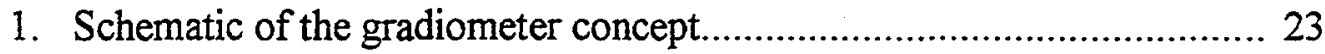

2. Model for Cloud Chamber simulations................................................. 24

3. Calculated $5 \mathrm{~m}$ gradiometer magnitude response................................. 25

4. Calculated $5 \mathrm{~m}$ EM gradiometer phase response................................. 25

5. Results of migrating the $30 \mathrm{kHz}$ calculated $5 \mathrm{~m} \mathrm{EM}$ gradiometer data to various depths....................................................................... 26

6. Phase of migrated $30 \mathrm{kHz}$ calculated results for the Cloud Chamber....... 26

7. Spatial spectrum for migrated $30 \mathrm{kHz}$ calculated $5 \mathrm{~m}$ gradiometer results 27

8. Survey for the Cloud Chamber.......................................................... 28

9. Magnitude of $30 \mathrm{kHz} 5 \mathrm{~m}$ gradiometer data for Line 18...................... 29

10. Phase results for the $30 \mathrm{kHz} 5 \mathrm{~m}$ gradiometer data for Line 18.............. 29

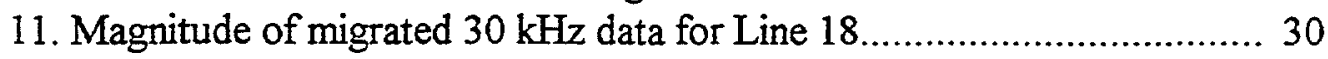

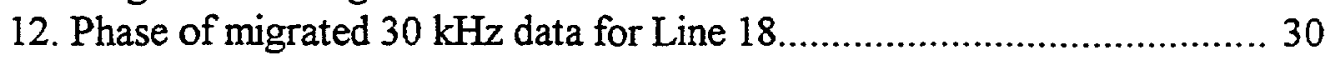

13. Migrated $30 \mathrm{kHz}$ data for Line 18 in wave vector space......................... 31

14. Amplitude 3-D surface for Cloud Chamber data at $30 \mathrm{kHz} \ldots \ldots \ldots \ldots \ldots \ldots \ldots . . . . . . . . .11$

15. Amplitude surface for Cloud Chamber data at $30 \mathrm{kHz}$ migrated to a depth of $8 \mathrm{~m}$ 
16. Amplitude surface for Cloud Chamber data at $30 \mathrm{kHz}$ migrated to a depth of $16 \mathrm{~m}$.

17. Yucca Mountain Tunnel Model.............................................................. 33

18. Calculated magnitude of the $5 \mathrm{~m}$ gradiometer response at $5 \mathrm{kHz} \ldots \ldots \ldots \ldots . . .33$

19. Calculated phase response for $5 \mathrm{~m}$ gradiometer at $5 \mathrm{kHz} \ldots \ldots \ldots \ldots \ldots \ldots \ldots \ldots . . . . . . . . . . .34$

20. Amplitude of migrated results for calculated $5 \mathrm{kHz}$ YMT data............... 34

21. Phase of migrated results for calculated $5 \mathrm{kHz}$ YMT data...................... 35

22. Wave vector amplitude of migrated calculated $5 \mathrm{kHz}$ YMT data............ 35

23. Yucca Mountain Tunnel survey..............................................................36

24. Amplitude results for YMT field data at $5 \mathrm{kHz}$ along the Road Line.........37

25. Phase results for field YMT data at $5 \mathrm{kHz}$ for the Road Line...................37

26. Amplitude results for migrated $5 \mathrm{kHz}$ YMT field data for Road Line........38

27. Phase of migrated results for $5 \mathrm{kHz}$ YMT field data for Road Line...........38

28. Amplitude of the difference of migrated data at the depths shown minus the migrated data at $50 \mathrm{~m}$ deep................................................39

29. Spatial spectrum of migrated $5 \mathrm{kHz}$ YMT Road Line data.......................39

30. Spatial spectrum of the comparison of normal migrated to differenced migrated $5 \mathrm{kHz}$ YMT Road Line data..............................40

31. 3-D Amplitude surface of the YMT $5 \mathrm{kHz}$ data...................................... 40

32. 3-D Amplitude surface of the YMT $5 \mathrm{kHz}$ data migrated down to the earth's surface.............................................................. 41

33. 3-D Amplitude surface of the YMT $5 \mathrm{kHz}$ data migrated down to a depth of $20 \mathrm{~m}$.

34. 3-D Amplitude surface of the YMT $5 \mathrm{kHz}$ data migrated down to a depth of $30 \mathrm{~m}$

35. 3-D Amplitude surface of the YMT $5 \mathrm{kHz}$ data migrated down to a depth of $40 \mathrm{~m}$

Tables

1. Location of data lines. 


\section{AN ELECTROMAGNETIC INDUCTION METHOD FOR UNDERGROUND TARGET DETECTION AND CHARACTERIZATION}

\section{INTRODUCTION}

\section{Background}

The United States interest in a capability to detect subsurface structures for security purposes became a research priority during the Vietnam War. The US interest was further intensified by two post-Vietnam events: the discovery of tunneling activity under the US embassy in Moscow and the Korean tunneling through the DeMilitarized Zone (DMZ). The US military encountered numerous subsurface command and control sites during the 1991 Gulf War. Part of the difficulty was separating militarily-significant underground sites from "civilian bomb shelters". Persistent rumors after the Gulf War were widely circulated suggesting the existence of underground SCUD missile storage facilities and nuclear, chemical, and biological weapons processing facilities. It is currently estimated that over 20 nations have, or are constructing underground facilities (Freeman and Cogbill, 1995). Several drug smuggling tunnels have been located on the United States southwest border. These tunnels were used as test areas for comparisons of technologies by the US Army Belvoir Research and Development Engineering Center (herein after referred to as BRDEC), 1993.

Detection, location and characterization of subsurface structures are some of the most challenging problems facing the military and counter proliferation communities. The problem of increasing our intelligence of underground structures requires a mix of efforts and information: human intelligence information, covert activities that may induce a hostile country to reveal likely locations, broad area search using airborne or satellite assets, military and cultural resource analysis for likely locations, geologic interpretation of reasonable construction sites, and development of geophysical tools for detection or verification. Geophysical techniques refer to sensing techniques that are capable of remotely observing the presence of a target by its effect on the local energy propagation (e.g. active electromagnetic, seismic or cosmic ray propagation) or local potential energy fields (e.g. magnetic, electromagnetic induction, or gravimetric fields). In 1994 a panel of national laboratory geophysicists undertook the assignment to assess the state of geophysical technologies to attack the underground facilities problem, assess the strengths of the national laboratories in these areas, and determine where best to focus efforts for optimal results. The findings of the panel study were used as guidelines for the DOE/NN20 program (Benchmark Study, 1994). The electromagnetic induction (EMI) project outlined in this report is an outgrowth of that study.

The effort at Sandia National Laboratories (SNL) is focused on a particular geophysical technique: active use of low-frequency EMI methods. Other sensing techniques are suitable for geophysical application. Examples include: passive 
electromagnetics, magnetics, and gravimetry. The active electromagnetic (EM) techniques presented here have useful application in a limited search area (several square kilometers), require close-in access to the surface (not more than hundreds of feet) around a suspected location, and at the present time are probably limited to overt searches, such as the UN inspection in Iraq or searches along borders where the US, allies, or UN control the surface. The utilization of both active and passive EM methods in a covert manner has not been thoroughly investigated. It is beyond the scope of this report to delve into possible covert strategies and deployment concepts.

Detection and location of underground structures using geophysical techniques are the most challenging problems facing the geophysical exploration community. The most significant difficulty is separation of the anomaly introduced by the underground structure from the natural variation in local geologies and surface and/or near surface targets. The sought-after target may be shallow or deep. The target may occur in a wide variety of geologic settings. As noted in BRDC (1993), " to be successful in detecting/locating a tunnel or a cavity requires combining the use of high resolution geophysical techniques having good depth penetration with advanced signal processing and interpretation techniques...". One of the conclusions of the BRDEC (1993) study was that active frequency-domain electromagnetic-gradiometer imaging system clearly demonstrated the capability to detect and define the (Otay Mesa) tunnel. While the tunnel conductor provides the strongest target, the surveys also demonstrated that the tunnel can be detected without the conductors when operated in the high frequency cross-borehole mode. The tunnel conductor (electric power line) was clearly detected using all methods. The results from the Otay Mesa experiment were the starting point for the research conducted within this study.

\section{Objectives and Scope.}

The overall objective of this work was to demonstrate detection of subsurface targets at depths of approximately 10 meters or more. Within this overall objective, specific objectives were: (1) to improve the EM gradiometer so that it measures multiple frequencies, provides accurate phase measurements, and personal computer-compatible digital recording of the responses (utilization of SNL LDRD funds), (2) to improve modeling of the basic geophysics including projection of the illuminating electromagnetic field and its coupling to the underground target (utilization of $D O E / N N-20$ and SNL LDRD funds), (3) to develop techniques for phase-based and multi-frequency processing and spatial processing to support subsurface target detection (DOE/NN-20 funded), and (4) conduct field surveys to evaluate the improved EM gradiometer for the detection and characterization of realistic underground targets (performed utilizing DOE/NN-20 funding).

This work successfully addressed all objectives. The potential utility of phase response for target detection was demonstrated and multi-frequency responses (third objective) were acquired. As part of the third objective, the EM wave migration algorithm was 
successfully applied to subsurface target detection and characterization. The wave migration method also demonstrated that this method filters responses from surface and/or near surface scatterers while retaining the response from the desired, deeper targets.

In this report, results will be discussed from surveys conducted at two Nevada Test Site (NTS) locations. These locations are the Cloud Chamber (CC) and the Yucca Mountain Tunnel (YMT). The depths to the tops of these two targets are approximately 5 and $30 \mathrm{~m}$, respectively. As will be discussed, the EM gradiometer approach was successful in detecting these two targets.

SNL sponsored an ellipticity method survey for imaging the YMT in a separate effort (Sternberg and Poulton, 1996) utilizing both LDRD and DOE/NN-20 funding. The results of this limited survey showed that this method can also detect the YMT. The numbers of survey lines that crossed the tunnel were limited so that the delineation of the tunnel was not as clear as with EM gradiometer survey discussed in this report. DOE (through Los Alamos National Laboratory) also sponsored a surveys over the CC and the YMT performed by GEOPHEX using their GEM-2 system (Cogbill, private comm.). The GEM-2 survey results showed a clear image of the CC but was unsuccessful in detecting the YMT.

This report is organized as follows: (1) description of the EM gradiometer, (2) discussion of the wave migration method, (3) modeling and field results from the CC along with the application of the wave migration method, (4) modeling and field results from the YMT along with the application of the wave migration method, and (5) some concluding remarks along with some recommendations.

\section{ELECTROMAGNETIC GRADIOMETER}

\section{Performance Goal}

The performance goal was to demonstrate detection of subsurface structures to depths exceeding tens of meters using EM techniques. These depths are beyond the performance range of ground penetrating radars for soils and overburdens having the likely range of conductivity (greater than 10 mhos/meter). Ground penetrating radars use frequencies in the $100 \mathrm{Mhz}$ region or above. EM frequencies applied to the improved gradiometer design ranged from kilohertz to hundreds of kilohertz. The man-made anomalies are assumed to be more conductive than the surrounding soil.

\section{Problem Description}

EMI techniques in the frequency range of interest have been shown to be effective for characterizing targets hundreds of meters beneath the surface (e.g. see, Electromagnetic methods in applied geophysics, 1987). They are also effective for environmental 
characterization at shallow depths, generally less than five meters. This work is directed at the "in between" region from 5 to 50 meters or so. Transmitters and receivers in the frequency ranges from $1-100 \mathrm{khz}$ are usually magnetic dipoles with air or ferrite cores rather than electric-field antennas. Stand-off, ground-based transmitters may be used to generate the induction field rather than placing the transmitter within several meters of the receivers. The standoff transmitter may be hundreds of meters or more removed from the receiver survey location. The standoff transmitter can be either an electric-field antenna (grounded wire on the surface having lengths of tens of meters) or a large current loop antenna (tens of meters on a side).

\section{EM Gradiometer Concept}

When the transmitter and receiver are directly coupled the so-called free-space primary field is many orders of magnitude larger than the desired scattered EM field. One way to remove the free-space primary is to configure the EM gradiometer receiver with oppositely wound coils separated by a fixed distance. The responses from the oppositely wound coils are 180 degrees out of phase and the total received signal is the sum of the signals received by the two receivers in the gradiometer. This creation of a gradiometer response is accomplished through signal subtraction utilizing hardware. An alternative is to subtract the signals through data processing that would require a large dynamic range since the free-space primary field is many orders of magnitude larger than the desired scattered field. As shown schematically in Figure 1, the primary field links the two receivers with approximately equal magnitude but $180 \mathrm{deg}$. out of phase resulting in a null for the primary field for the combined received signal from both receivers. The scattered field also links the two receivers; however, unless the two receivers are equidistant from the scattering target, the scattered field is not completely canceled. In addition, the host response is minimized. This configuration measures the gradient of the magnetic field.

There are several transmitter-receiving gradiometer configurations that can be used. Two deployment concepts have been modeled and tested. Of these two, each has its own strengths and weaknesses.

One deployment strategy is to use a fixed location for the transmitter where the transmitting antenna may be a grounded electric dipole or a loop of wire on the surface of the earth forming a vertical magnetic dipole (VMD). For the work discussed in this report, the VMD was used rather than the grounded electric dipole. For this configuration the gradiometer receiving antennae are horizontal magnetic dipoles (HMD) aligned parallel to the surface of the earth and perpendicular to the edge of the VMD as shown in Figure 2. In this configuration the receiving HMD's of the gradiometer are not equidistant from the VMD source; thus, the free-space primary and the host response are not completely canceled. When the distance from the receiving gradiometer to the transmitting antenna is large, then the free-space primary and host responses can be kept small so that the target response is a significant fraction of the total response. The 
advantage of this configuration is from an operational stand point since the transmitting antenna remains fixed during a survey with a roving gradiometer receiver.

A second deployment strategy is to use a HMD transmitting source with HMD receivers in the gradiometer where the geometrical relationship remains fixed. The transmitting antenna is co-linear with the gradiometer and is located on a perpendicular to the center of the gradiometer at a fixed distance away. This configuration will be referred to as the symmetric mode. With this configuration the free-space primary and the host response are zero and there is only a target response. The disadvantages of this concept are that a precise geometrical relationship must be maintained to zero out the free-space primary and host responses and both transmitting and receiving antennae must be moved during a survey.

In the field tests discussed below, the fixed transmitting VMD concept was used primarily. A limited survey was performed to test the symmetric mode deployment strategy. The results of using the symmetric mode are reported elsewhere (Cress et al., 1996).

\section{WAVE MIGRATION}

In previous work, the migration of EM data has been demonstrated (Sasaki, 1989; Bartel, 1992; Bartel, 1994). That previous work was based on the "exploding reflector" model as used in the migration of seismic data (Lowenthal, et al., 1976). Schneider (1978) presented an integral equation formulation for migration where the problem is posed as a boundary value problem. The scalar seismic data measured over a surface aperture is migrated (extrapolated) downward using the scalar form to Green's theorem. Bartel (1994) showed that under the condition that the Green's function vanishes at the surface of the earth, i.e. on the aperture, the vector formulation of Green's theorem reduces to the scalar form. The integral approach is similar to classical optical diffraction theory (Goodman, 1968,3-35).

There are a number of ways to derive the migration equation. The simplest derivation is to use Helmholtz equation (e.g., Ward and Hohmann, 1987, p 136). In the absence of sources and for time dependent solutions of the form $\exp (i \omega t)$, the magnetic field $\vec{H}$ (and hence the gradient of the field) satisfies the equation

$$
\nabla^{2} \vec{H}+k^{2} \vec{H}=0,
$$

where

$$
\begin{aligned}
k^{2} & =\omega^{2} / c^{2}, \text { in free space and } \\
& =-i \omega \mu \sigma, \text { in the earth in the quasi-static limit }
\end{aligned}
$$


Here $\omega$ is the angular frequency ( $2 \pi$ times the frequency), $\mathrm{c}$ is the wave speed in air of $3 \times 10^{8} \mathrm{~m} / \mathrm{s}, \mu$ is the magnetic permeability (one usually uses the free space value of $4 \pi \times 10^{-7}$ henrys $/ \mathrm{m}$ ), and $\sigma$ is the conductivity. For a limited discussion of electromagnetic (EM) waves in earth materials and a discussion of migration in one dimension see Bartel (1992).

To reduce equation (1) to an equation which only depends upon the depth $z$, a spatial Fourier transform is taken over the $x$ and $y$ directions

$$
\left(-k_{x}^{2}-k_{y}^{2}+\partial^{2} / \partial z^{2}\right) \hat{H}\left(k_{x}, k_{y}, z\right)=0
$$

Solutions to equation (3) are

$$
\hat{H}\left(k_{x}, k_{y}, z\right)=\hat{H}\left(k_{x}, k_{y}, 0\right) \exp ( \pm \kappa z)
$$

where

$$
\kappa=\left(k_{x}^{2}+k_{y}^{2}-k^{2}\right)^{1 / 2}
$$

and $k^{2}$ is given by equation (2) in the air and in the earth. $\hat{H}\left(k_{x}, k_{y}, z\right)$ is the spatial Fourier transform of the migrated or extrapolated data, and $\hat{H}\left(k_{x}, k_{y}, 0\right)$ is the spatial Fourier transform of the data taken over the surface aperture in the $x-y$ directions. Note that the aperture can be on the surface of the earth $(z=0)$ or in the air at $z=-h$. If the aperture is in the air, the data should be migrated down to the surface of the earth using $\kappa=\left(k_{x}^{2}+k_{y}^{2}-\omega^{2} / c^{2}\right)^{1 / 2}$ and then using $\kappa=\left(k_{x}^{2}+k_{y}^{2}+i \omega \mu \sigma\right)^{1 / 2}$ for migrating in the earth. Equation (5) is often called the dispersion relation for the wave equation, equation (1).

It is noteworthy that equation (4) can be derived from the integral Green's theorem formulation by utilizing Fourier transforms of the data and the Green's function and performing an integration over the wavevector representing the transform pair of the depth $z$. In performing the contour integration in the derivation, the negative sign in equation (4) is a natural consequence. More on the choice of sign will be discussed later.

The + sign in Equation (4) indicates a growing exponential, whereas the - sign indicates a decaying exponential. For $k_{x}^{2}+k_{y}^{2}<k^{2}, \kappa$ will have a significant imaginary part and the waves will have a significant oscillatory component. Since for this case in the earth $k^{2}$ is imaginary, the waves will suffer attenuation even when $k_{x}^{2}+k_{y}^{2}<k^{2}$. When $k_{x}^{2}+k_{y}^{2}>k^{2}$ the real part of $K$ dominates. When $k_{x}^{2}+k_{y}^{2}>k^{2}$ the waves are referred to as evanescent waves that fade away rapidly with distance when the negative sign is used or grow rapidly with distance when the positive sign is used. To illustrate this, it is 
instructive to expand $\exp ( \pm \kappa z)$ for small and large values of $\eta^{2}=k_{x}^{2}+k_{y}^{2}$ for waves in the earth. Expanding

$$
\begin{aligned}
& \exp ( \pm \kappa z) \rightarrow \exp \left[ \pm i \xi\left(1-\frac{\eta^{2}}{4 \xi^{2}}\right) z \pm \xi\left(1+\frac{\eta^{2}}{4 \xi^{2}}\right) z\right] \text { when } \eta^{2}=k_{x}^{2}+k_{y}^{2}<<i \omega \mu \sigma \\
& \exp ( \pm \kappa z) \rightarrow \exp \left[ \pm \eta\left(1+\frac{i \xi^{2}}{\eta^{2}}\right) z\right] \text { when } \eta^{2}=k_{x}^{2}+k_{y}^{2}>>i \omega \mu \sigma,
\end{aligned}
$$

where $\xi=\sqrt{\omega \mu \sigma / 2}$. Upon examination of equation (6), the effects of the migration medium contained in $\xi$ are more pronounced for small values of $\eta$ than for large values of $\eta$.

The choice of sign in equation (4) is important because it determines the direction of extrapolation. The waves emanating from a subsurface source are diverging waves and are of the form $\exp (k z+i \omega t)$, that is, a wave traveling from the subsurface source toward the surface when $k_{x}^{2}+k_{y}^{2}<k^{2}$. Following Schneider (1978) the use of the positive sign reflects the phase delay in propagation from the subsurface source. Note that Schneider (1978) used a time dependence of $\exp (-i \omega t)$ where here the time dependence is $\exp (i \omega t)$. Conversely, the clock can run backward and the field closer to the source can be computed by use of the negative sign to reflect the phase advance in moving a distance $z$. In order to obtain the proper phase for waves migrated (extrapolated) downward, waves of the form $\exp (-k z+i \omega t)$ are to be used. The choice of sign is thus the negative sign in equation (4). For the Green's theorem integral equation approach, the negative sign is a natural consequence of the contour integration leading to extrapolation of the surface values of the fields to the interior of volume bounded by the surface.

It is noteworthy that when data is only taken along a single line, the aperture is one dimensional. In the one-dimensional case, the spatial Fourier transform is only along one direction and the functions depend only on one wavevector value.

The field values as a function of $x$ and $y$ can be found by the inverse Fourier transform of equation (4). The inverse Fourier transform of equation (4) is

$$
\vec{H}(x, y, z)=(1 / 2 \pi)^{2} \int d k_{x} d k_{y} \hat{H}\left(k_{x}, k_{y}, 0\right) \exp (-\kappa z) \exp \left(i k_{x} x\right) \exp \left(i k_{y} y\right),
$$

where $\mathrm{K}$ is defined by equations ( 2 and 5 ). The migrated (or extrapolated) field data given by equation (7) are in effect spatially filtered by the $\exp (-\kappa z)$ term. With using the - sign, $\exp (-\kappa z)$ acts as a low-pass filter on $\hat{H}\left(k_{x}, k_{y}, 0\right)$ where the filter restricts the $k_{x}, k_{y^{-}}$ values contributing to the inverse Fourier transform as the depth $z$ increases. The filter 
action of the migrated data will be illustrated during the discussions of calculated and actual field data below.

\section{FIELD TESTS}

\section{Purpose}

The purposes of the series of tests conducted at the NTS were to test the EM gradiometer concept and the equipment built by Raton Technology Research (RTR) on realistic, underground facilities targets. The targets were the Cloud Chamber and the Yucca Mountain tunnel. The RTR equipment was selected for evaluation because of their success in imaging coal seams using EM methods (Stolarczyk, 1991) and the use of their equipment in the EM gradiometer mode to detect the Otay Mesa tunnel (BRDEC, 1993).

\section{Cloud Chamber}

The Cloud Chamber (CC) is located on north-central Yucca Flat, an alluvial basin on the NTS that has been used repeatedly for underground nuclear tests. The CC location is approximately $70 \mathrm{~km}$ north of the NTS access gate, a short distance east of the Mercury highway. The approximate geographic coordinates of the center of the $\mathrm{CC}$ are latitude 37 degrees 08 minutes 40.67 seconds North, longitude 116 degrees 04 minutes 08.65 seconds. Nevada State Plane coordinates of the CC are N. 872,168 ft., E. 674,174 ft. (1927 NAD).

The $\mathrm{CC}$ is an underground structure shaped like a Quonset hut. It is $42.7 \mathrm{~m}$ in length and $9.75 \mathrm{~m}$ wide at its base; its maximum height is $4.9 \mathrm{~m}$. Its total volume is approximately $1600 \mathrm{~m}^{3}$, not including the volume of the equipment access shaft that leads to the surface from the $\mathrm{CC}$. It is oriented with its long dimension pointing N70 deg E. The reinforced-concrete base of the CC is approximately $9 \mathrm{~m}$ below grade, implying that the $\mathrm{CC}$ roof comes within approximately $5 \mathrm{~m}$ of the ground surface. The CC itself is a largely wooden structure, with the wood lagging making up the building supported by semicircular steel rib members. Access to the surface area above the CC is unrestricted except for small areas in the immediate vicinity of the emergency egress stairway and an equipment access shaft. However, access to the $\mathrm{CC}$ itself is prohibited for safety reasons, as the structure has been inactive since 1968. Off-road vehicle traffic is prohibited at the CC site.

\section{Model Calculation Results}

Figure 2 shows a model for the $\mathrm{CC}$ along with a schematic of the deployment strategy. For the model calculations the transmitting loop antenna is $120 \times 100 \mathrm{~m}$ with the front edge 
located $200 \mathrm{~m}$ from the center line of the target. A background resistivity of $50 \Omega \bullet \mathrm{m}$ was used. Calculations of responses were performed through the center of the target as shown. The integral equation computer code of Newman, et al. (1986) was used for the calculations.

Figure 3 shows the magnitude of the $5 \mathrm{~m}$ gradiometer response for the given frequencies. Note that the gradient results have not been divided by the separation between the two receivers. Calculations were performed at one meter above the earth's surface. The gradient response was determined from calculated magnetic field values by subtracting the response at $x$ from the response at $x+5 \mathrm{~m}$. The component of the gradient response is that component perpendicular to the near edge of the transmitting loop. As expected, the largest magnitude responses are for frequencies of $30 \mathrm{kHz}$ and $60 \mathrm{kHz}$. The characteristic gradiometer response is that there are local maxima and minima on either side of the center line of the target. The center line of the target is at zero distance. Note that the response with the target in place crosses over the response with no target at the position of the center line of the target indicative of zero target response directly over the target.

The phase responses are shown in Figure 4. The largest phase responses are for frequencies of $60 \mathrm{kHz}$ and $100 \mathrm{kHz}$. At $100 \mathrm{kHz}$ the difference in the phase between the peak and the valley is over 60 degrees. As with the magnitude results discussed above, the phase as a function of distance with the target in place crosses the phase as a function of distance with no target (not shown) again indicative of cancellation of the target response when directly over the target.

To illustrate the analysis of the data using the migration method discussed above, the $30 \mathrm{kHz}$ calculated results were migrated using a one-dimensional spatial Fourier transform. For the results of the migration shown in Figure 5, the data were migrated from the 1-D aperture $1 \mathrm{~m}$ above the earth down to the earth's surface using the freespace value of $k^{2}$ in equations ( 2 and 5 ) and down to the migration depth in the earth using the quasi-static limit value of $k^{2}$. A resistivity of $50 \Omega \bullet m$ was used in equations (2 and 5) for the migration of the data in the earth. Shown in the figure are migration results with and without the target in place.

The magnitudes of the migrated data are shown in Figure 5. The results for $0 \mathrm{~m}$ migration depth shown in Figure 5 represent the original data migrated down to the earth's surface. The local maximum and local minimum on either side of the center line of the target are characteristic of the gradiometer response. As the migration depth increases the local maximums are reduced while the local minimums initially increase from their original value and then decrease and broaden. At $12 \mathrm{~m}$ the local maxima and local minima have almost disappeared indicative of the depth to the bottom of the target at $9 \mathrm{~m}$. At 16 $\mathrm{m}$ the results with the target in place have almost returned to the background value without the target in place. Note the center line of the target is at zero distance and the target is $10 \mathrm{~m}$ wide at its base. The phases of the migrated data are shown in Figure 6 . As 
the migration depth increases, the characteristic rapid phase change over the target starts to disappear.

The filtering action of the act of migrating data is illustrated by the spatial spectrum shown in Figure 7. In the figure, comparisons are made for the original data migrated to the earth's surface $(0 \mathrm{~m}$ migration) to results migrated to depths of $8 \mathrm{~m}$ and $16 \mathrm{~m}$ for both when the target is in place and for the background without the target in place. In Figure 7 , the contributions of the large positive and negative values of the wavevector, $k_{x}$, are small since $\exp (-\kappa z)$ acts as a low-pass filter. Comparison of the results with and without the target in place shows the contributions of the target in wavevector space. Since the larger values of the absolute values of the $k_{x}$ do not contribute significantly, the effects of the medium have an influence, i.e., $i \omega \mu \sigma$ in equations ( 2 and 5) contributes to the migration results. The contributions to the migration results can be seen by examining equation (6) for the expansion of the small and large limits of $k_{x}$. The characteristic cusp minimums in the figure with the target in place are separated by $\Delta k_{x} \approx 0.15 / \mathrm{m}$ corresponding to a wavelength of approximately $42 \mathrm{~m}$. This wavelength of $42 \mathrm{~m}$ corresponds to the length of the target contribution in the unmigrated data (see Figure 3 or 5). In addition the cusp minimums decrease as the migration depth increases leading to the defocusing of the target. Note that in the figure, the results are symmetric about $k_{x}=0$.

\section{Field Survey design}

Figure 8 is a sketch of the survey, which is not to scale. The transmitting antenna was a loop $125 \times 100 \mathrm{~m}$ with the long side in the E-W direction and located $200 \mathrm{~m}$ toward the North of the long axis center line of the $\mathrm{CC}$. Fences around an old crater prevented the transmitting antenna from extending any farther east. The survey lines are in the northsouth direction and cut the long axis center line of the $\mathrm{CC}$ at an angle of approximately 70 deg. (The long axis of the CC points N70 deg. E.) The separation of the survey lines was $8 \mathrm{~m}$ with a total length of $100 \mathrm{~m}$ centered on the long axis center line of the CC as shown in Figure 8. The surveyed area was $104 \times 100 \mathrm{~m}$. This survey area size was chosen so that a comparison could be made to the GEM-2 data taken by GEOPHEX (Cogbill, private comm.). The horizontal receiving EM gradiometer dipoles are parallel to the survey lines and perpendicular to the near side of the transmitting antenna.

\section{Data Collection}

1. Data were collected in a stop-and-go manner every $2.5 \mathrm{~m}$ along the survey lines for the fixed loop transmitting antenna, and a total of 52 measurements were made along each survey line. 
2. The frequencies used were: $100 \mathrm{kHz}, 60 \mathrm{kHz}, 30 \mathrm{kHz}, 10 \mathrm{kHz}$, and $5 \mathrm{kHz}$. Data at these frequencies were acquired sequentially at each stop-and-go data station.

\section{Survey and Migration Results}

In what follows, only the $30 \mathrm{kHz}$ data will be discussed. These data appeared to display the CC target the best and were the most stable. Figure 9 shows the magnitude of the gradiometer response over the CC for Line 18 that is at a distance of $x=68 \mathrm{~m}$ from the origin as shown in Figure 8. The gradiometer phase is shown in Figure 10. Data taken on an approximate $2.5 \mathrm{~m}$ spacing were interpolated using a spline fit to data station spacing of $2 \mathrm{~m}$. From Figure 8 , the center line of the target appears to be at a $y$-distance of approximately $47 \mathrm{~m}$. Comparing the magnitude and phase data (Figures 9 and 10) to the calculated results (Figures 3 and 4), there are some differences. First the magnitudes of the field data show a spatially sharp null (or minimum) apparently over the center line of the target with local maximums on either side of the center line of the target. Second, the field data phase shows a larger change over the apparent center line of the target than predicted by the model calculations. The reason for these differences may be due to several factors. First, there are multiple targets contributing to the total response. These multiple targets include the $\mathrm{CC}$, as well as the cables on the ground in the northern part of the survey area. Second, the CC is not a solid conductor as was used in the model calculations. In addition, the survey line is not perpendicular to the long axis of the $\mathrm{CC}$ as for the model calculations. Finally, the modeling code used to produce the model results was not designed to handle large resistivity contrasts as exist between the host and the CC (Newman, et al., 1986). However, there are overall similarities of the field and model data. In the region of N-to-S distance of $0-20 \mathrm{~m}$ there were metal cables on the surface giving rise to the behavior of the field data in that region.

The one-dimensional migrated data for Line 18 are shown in Figures 11 and 12 for the magnitude and phase of the migrated data, respectively. In the figures, the $0 \mathrm{~m}$ migration depth is the original gradiometer data migrated down to the earth's surface.

In Figure 11, the null in the magnitude over the apparent centerline of the target is maintained down to a migration a depth of $8 \mathrm{~m}$ and is defocused at a migration depth of $16 \mathrm{~m}$ that is believed to below the bottom of the target. The spatially sharp null appearing at a $\mathrm{N}$-to-S distance of approximately $10 \mathrm{~m}$ defocuses at migration depths in excess of approximately $4 \mathrm{~m}$ indicative of a shallow target. Note that some of the spatially irregular behavior evident in the original data have disappeared as the data are migrated downward. This indicates that the response believed to be that of the target is indeed due to the CC. The act of migrating data filters responses due to near surface geologic noise as discussed above. The results of the migrated phase are shown in Figure 12. Here the sharp phase response over the target is retained even to a migration depth of $16 \mathrm{~m}$. However, the slope of the sharp phase response softens as a function of migration depth and the trough in the phase over the target disappears as the migration depth increases. 
For Line 18 the one-dimensional, spatial spectrum magnitude of the migrated data is shown in Figure 13. The magnitude of the original data migrated to the earth's surface ( 0 $m$ migration depth) is not symmetric about the wavevector equal to zero as it was for the calculated results. The reason for the asymmetry is that there are multiple scattering responses in the field data. Note that in both figures, as the migration depth increases, the amplitude becomes more symmetric and is smoother than the unmigrated data. The process of migration acts as a low-pass filter. As the data are migrated downward, the contributions of near-surface scatterers decrease leading to a smoother, more symmetric amplitude as only deeper targets and the earth response contribute. It is beyond the scope of this report to examine target discrimination utilizing various parts of the wavevector spectrum.

The three-dimensional (3-D) data surfaces are shown in Figures 14-16. Figure 14 shows the 3-D surface of the original $30 \mathrm{kHz}$ magnitude data (unmigrated). Figures 15 and 16 show the $30 \mathrm{kHz}$ data migrated to a depth of $8 \mathrm{~m}$ and $16 \mathrm{~m}$, respectively. The view for these figures is looking from the Southwest corner of the area survey toward the Northeast which is essentially along the axis of the $\mathrm{CC}$. The separation between the grid lines in the W-to-E direction is $8 \mathrm{~m}$, while the separation in the N-to-S direction is $2 \mathrm{~m}$.

The null/trough in the data along the axis of the $\mathrm{CC}$ is apparent in the data shown in Figure 14. On either side of the trough are local maximums. There is a hint of the line-ofsight pipe extending from the $\mathrm{CC}$ to the Northeast. On the northern side (top portion of the figure) of the area surveyed, there are several cables on the ground. An above ground power panel is located approximately at coordinates $36 \mathrm{~m}$ in the W-to-E direction and 30 $\mathrm{m}$ in the $\mathrm{N}$-to-S direction. At this location there is a slight local maxima in the data. A surface concrete pad is located at approximate coordinates of $44 \mathrm{~m}$ in the W-to-E direction and $88 \mathrm{~m}$ in the $\mathrm{N}$-to-S direction. There does not seem to any apparent signature associated with the concrete pad. A surface metal vent to the CC is located at approximate coordinates of $52 \mathrm{~m}$ in the W-to-E direction and $50 \mathrm{~m}$ in the N-to-S direction. At this location in Figure 14, there is a local minimum.

Figure 15 shows the results of the magnitude of the $30 \mathrm{kHz}$ data migrated to a depth of $8 \mathrm{~m}$. To the southern side of the CC there is the gradiometer characteristic local maxima indicative of the $\mathrm{CC}$ target. The local maxima on the northern side of the $\mathrm{CC}$ is less well defined. The local maximum at coordinates $44 \mathrm{~m}$ (W-to-E), $15 \mathrm{~m}$ (N-to-S) and $80 \mathrm{~m}$ (W-to-E), $15 \mathrm{~m}$ (N-to-S) are probably associated with vestiges of the response of surface and near surface cables and the characteristic general trend for the VMD source located to the North of the surveyed area. The depression in the central part of the figure is associated with the $\mathrm{CC}$. It appears that the "near" extension of the $\mathrm{CC}$ is at coordinates $32 \mathrm{~m}$ (W-to-E), $54-56 \mathrm{~m}$ (N-to-S) which is in agreement with the believed position of this edge of the CC, see Figure 8. It also appears that the East-Northeast extremity of the CC is at a position of $84 \mathrm{~m}$ (W-to-E), $48 \mathrm{~m}$ (N-to-S), again in general agreement with the believed location of the $\mathrm{CC}$. The line-of-sight pipe is evident in the migrated data. Figure 16 shows the amplitude surface at a migrated depth of $16 \mathrm{~m}$. The anomaly associated with the $\mathrm{CC}$ has all but vanished indicating the depth of the $\mathrm{CC}$ is shallower than $16 \mathrm{~m}$. 


\section{Summary of the Cloud Chamber Results}

The RTR equipment used for the acquisition of EM gradiometer data functioned overall in an acceptable manner. However due to some equipment problems, data from all the frequencies could not be used. For the $\mathrm{CC}$, efforts were concentrated to obtain reasonably good $30 \mathrm{kHz}$ data. In general this was accomplished. Absolute phase referencing is a problem for the deployment strategy used; however, for the gradiometer approach this absolute phase referencing is not necessary since the transmitter phase cancels for the gradiometer method.

The data display quite a bit of spatial variation. The sources of this variability are the near-surface clutter at the $\mathrm{CC}$ site, small variations of the transmitter current with time, and the fact that the gradiometer may not have been completely stationary or level when the data were collected. This variability is evident in the unmigrated data shown in Figures 9,10 , and 14 . The wave migration process acts as a filtering operation to the data. The migration process tends to mitigate the effects of near surface scatterers while keeping the signature of the $\mathrm{CC}$. From the results of the migration, the location of the CC is apparent; however, the actual geometrical shape and depth of the $\mathrm{CC}$ are not readily apparent. Although the $\mathrm{CC}$ is somewhat apparent in the raw, original data, there was significant surface clutter to partially mask the presence of the CC. The migration method removes a significant portion of the surface clutter while retaining the $\mathrm{CC}$ and line-of-sight pipe signatures. The single frequency migration method appears to estimate a maximum depth of the target; whereas, the depth to the top of the target is less clear.

The use of multiple frequencies is essential to accurately locate and characterize a subsurface target when using the migration method. When the migrated results contain different frequencies there is interference of the waves. The assumption is made that for the scattered fields, the waves at different frequencies are in phase at their origin at zero time. Thus summing the migrated results as a function of frequency is in effect taking the frequency Fourier transform at time zero and the origin of the scattered wave is where the phase is a minimum (Claerbout, 1971; Lowenthal, et al, 1976; Schneider, 1978; Bartel, 1992; Bartel, 1994). Unfortunately for the data acquired at the CC, multiple frequency data are not available. Even though a single frequency was used for the migration, the CC target is apparent.

A strength of the gradiometer approach is that targets can be detected. In fact its greatest asset is to detect long narrow targets such as wires. The migration analysis method can give information on location and depth and an estimate of the length of a long, narrow target; however, the width of a long-narrow target is not readily apparent at least for single frequency data.

The utilization of the spatial frequency spectrum to separate targets appears fruitful. A limited look at this (not shown) suggests that the central portion of the spectrum shown in 
Figure 13 retains the characteristic response of the $\mathrm{CC}$, while the plus and minus halves of the spectrum may yield other information about additional scatterers. It is beyond the scope of this report to delve into this any further.

\section{Yucca Mountain Tunnel}

The Yucca Mountain Tunnel (YMT) is located on the west edge of the NTS. This tunnel is under construction for nuclear waste storage. The tunnel is approximately $10 \mathrm{~m}$ wide and $10 \mathrm{~m}$ tall. There is some metal lagging depending upon the rock competency. The tunnel contains railroad tracks, power cables, and metal pipes. The tunnel is being constructed using a tunnel boring machine. At the survey area, the tunnel is approximately $30 \mathrm{~m}$ deep to the roof of the tunnel. In the survey area the land surface is relatively flat and there is a dirt roadway crossing the tunnel at nearly a right angle.

\section{Model Calculation Results}

Model calculations were performed to aid in the planning of the survey and in the interpretation of the YMT data. The model used is shown in Figure 17. Note that in the model the tunnel cross-section is $4 \times 4 \mathrm{~m}$, whereas the actual cross-section of the tunnel is approximately $10 \times 10 \mathrm{~m}$. The loop size used was $200 \times 100 \mathrm{~m}$ located $200 \mathrm{~m}$ from the target. The magnetic field components perpendicular to the long edge of the loop were calculated at a distance of one meter above the surface.

Model calculations showed that the frequency of $5 \mathrm{kHz}$ gave a larger response to the target than for the higher frequencies $(10,30,60$, and $100 \mathrm{kHz})$. Figure 18 shows the calculated $5 \mathrm{~m}$ gradiometer magnitude response at $5 \mathrm{kHz}$. The center line of the target is located at zero distance. The solid line shows results with the target in place and the dashed line in the absence of the target. Figure 19 shows the phase response for the $5 \mathrm{~m}$ gradiometer response at $5 \mathrm{kHz}$. For the target at a depth of $30 \mathrm{~m}$, the target response is still evident even out to distances of $80 \mathrm{~m}$ from the target.

The results for the magnitude and the phase of the migrated calculated results are shown in Figures 20 and 21, respectively. The resistivity of the host is assumed to be 500 $\Omega \bullet \mathrm{m}$. The migrated results at $0 \mathrm{~m}$ are the results of migrating the calculated data $1 \mathrm{~m}$ above the earth's surface down to the earth's surface. Unlike the Cloud Chamber results, the magnitude and phase with the target in place do not return to the background response even to a depth of $50 \mathrm{~m}$ (not shown). From an examination of the Figure 20, the magnitude at a migration depth of $40 \mathrm{~m}$ is flat across the location of the target, while at 30 $\mathrm{m}$ there is a slight dip in the magnitude of the migrated data. On the other hand, the phase of the migrated results at $40 \mathrm{~m}$ migration depth with the target in place are not parallel to the results with no target. The failure of the magnitude and phase migrated results to return to the background values may be due in part to the shortness of the 1-D aperture. 
The spatial spectrum of the magnitude for the migrated results is shown in Figure 22 for the YMT $5 \mathrm{kHz}$ calculated data. Note that the target response is only evident for the wavevector values near zero even for the $0 \mathrm{~m}$ migration depth. The amplitude is not quite symmetric about the wavevector equal to zero as it was for the Cloud Chamber calculated results. The length of the target disturbance in wavevector space is not evident as it was for the Cloud Chamber calculated results (Figure 7); this fact may lead to the slight asymmetry of the spectrum. This is probably due to the shortness of the 1-D aperture; i.e., at the ends of the calculated results, the calculated data with the target in place are not equal to the calculated data with no target in place. Further work is needed to confirm these assertions.

\section{Survey Design}

Figure 23 shows a sketch of the survey that is not to scale. The transmitting antenna is a $200 \times 100 \mathrm{~m}$ loop with the long side perpendicular to the existing roadway. The near edge of the loop is located $200 \mathrm{~m}$ from the presumed location of the tunnel. One survey line is down the road way with a length of $400 \mathrm{~m}$ and came within $50 \mathrm{~m}$ of the near edge of the transmitting loop. The "outlying" survey lines are spaced as shown with their lengths nominally $200 \mathrm{~m}$ long centered on the tunnel. The horizontal receiving dipole's axes of the gradiometer are parallel to the survey lines.

In addition to the above primary survey, the symmetric mode concept, discussed above, was tested. The transmitting antenna was a HMD with its axis parallel to the axis of the gradiometer and off-set $25 \mathrm{~m}$ from the axis of the gradiometer receiver. This concept may be easier to deploy is some situations. Results of this survey are reported elsewhere (Cress, et al., 1996).

\section{Data Collection}

1. Data were collected in a stop-and-go manner every $5 \mathrm{~m}$ along the survey lines for the fixed loop transmitting antenna, and a total of some 40 measurements along each survey line depending upon which line.

2. Due to the depth of the target only a frequency of $5 \mathrm{kHz}$ was used.

\section{Survey and Migration Results}

The magnitude and phase data for the results taken along the road in Figure 23 (herein after referred to as the Road Line) are shown in Figures 24 and 25, respectively. Note that for these data, as well as for the other lines, a spline fit to the data was performed to give a spacing of $2.5 \mathrm{~m}$ between the data points. The magnitude of the gradiometer response shows a dramatic decrease over the presumed location of the tunnel at $141 \mathrm{~m}$. Unlike the Cloud Chamber data, the magnitude does not "recover" to give a pronounced 
minimum in the response. However, there is a small local minimum in the magnitude results at a N-to-S distance of $140 \mathrm{~m}$. The phase data, however, do show the dramatic change over the presumed midpoint of the tunnel like the Cloud Chamber data. The rapid phase change occurs between 140 and $145 \mathrm{~m}$. The magnitude data do not resemble the calculated results (Figure 18), whereas the phase data do resemble the calculated phase results (Figure 19) except for "direction" of the change. As the distance from the transmitter increases, the calculated results go from a larger phase value to a smaller value; whereas, the field results go from a smaller value to a larger value as the target is crossed. This 180 degree phase difference is due to which receiver in the gradiometer is considered positive and which is considered negative. The distinction is somewhat arbitrary. The definition of receivers in the gradiometer will not affect the magnitude, however.

The behavior of the magnitude may be due to the fact that at the large distances from the transmitter, the field strengths are small. The distances in Figures 24 and 25 are distances to the near edge of the transmitting loop antenna. A significant null in the magnitude may be masked by the signal being small and near the noise floor for distances beyond the tunnel. However, the phase data remains quite stable out to distances of 250 $\mathrm{m}$, and is not erratic as one would probably obtain if the signal is well below the noise floor.

The results for the magnitude and phase of the migrated data for the Road Line are shown in Figures 26 and 27, respectively. The resistivity of the host is assumed to be 500 $\Omega \bullet m$. Here as for the Cloud Chamber results, the $0 \mathrm{~m}$ migrated data are the field data migrated from $1 \mathrm{~m}$ above the earth's surface down to the earth's surface. It is noteworthy that the small local minimum at $140 \mathrm{~m}$ in the field data at $1 \mathrm{~m}$ above the earth's surface is evident in the results migrated down to the earth's surface but disappears even for a shallow migration depth of $5 \mathrm{~m}$. The migration depths of 10,20,30, and $40 \mathrm{~m}$ are depths below the earth's surface. The presumed depth of the YMT is approximately $30 \mathrm{~m}$ in this location. From an examination of the figures, both the magnitude and phase begin to flatten losing the behavior exhibited at the surface. At a $40 \mathrm{~m}$ migration depth, the magnitude and phase responses become nearly flat indicating that $40 \mathrm{~m}$ may be below the depth of the YMT. The location of the YMT is evident in both the magnitude and phase data; however, the depth to the tunnel is not evident in these results.

To enhance the target response, Figure 28 shows the amplitude of the data migrated down to the depth indicated minus the data migrated down to a depth of $50 \mathrm{~m}$. The rationale for doing this subtraction is to minimize the host and transmitter response and enhance the target response. The local minimum at a N-to-S distance of $135 \mathrm{~m}$, presumed to be associated with the tunnel at $141 \mathrm{~m}$, that is evident in the $0 \mathrm{~m}$ migration depth shifts to larger values of the N-to-S distance as the migration depth increases. This local minimum all but vanishes at the migration depth of $40 \mathrm{~m}$. At a migration depth of $30 \mathrm{~m}$, this local minimum has shifted to a N-to-S distance of $145 \mathrm{~m}$. It appears that the removal of the deep migrated data from the shallow migrated data does enhance the target response. 
The target enhancement by differencing the migrated data as discussed above is evident by comparing the spatial spectrum for the normal migrated data, Figure 29, and the spatial spectrum for the differenced migrated data. This comparison is shown in Figure 30 for the original data migrated to the earth's surface and data migrated to $20 \mathrm{~m}$ depth. From an examination of Figure 30, apparently the act of differencing the data in $x$ $y$ space and then performing a Fourier transform to wavevector space enhances the contributions of the larger values of the wavevector. By subtracting some sort of base line, the spatial spectrum for the differenced data, Figure 30, appears to reduced the effect of the low-pass filter effects of migration. This differencing enhances the small minimum associated with the tunnel by allowing the higher values of the wavevector to contribute to the inverse Fourier transform.

The 3-D amplitude surface of the original data is shown in Figure 31. The zero distance in the W-to E direction is along the road way in Figure 23. The presumed location of the tunnel runs from approximately the coordinates W-to-E -50 m, N-to-S 119 $\mathrm{m}$ to W-to-E $65 \mathrm{~m}, \mathrm{~N}$-to-S $176 \mathrm{~m}$. The small local minimum associated with the YMT is apparent along this general direction. The large values of the amplitude along the line at $\mathrm{W}$-to-E $65 \mathrm{~m}$ at the position of N-to-S $\sim 200 \mathrm{~m}$ are due to the presence of a surface, metal fence enclosing a vegetation test area. Note that for some of the lines, data were not acquired all the way out to a $\mathrm{N}$-to-S distance of $250 \mathrm{~m}$. Table 1 summarizes the data taken along the various lines. In order to complete the data surface, data were extended to the ends of the lines as indicated in the table. For the extension to the end of the line, the real and quadrature parts were extended using the last reliable data point to give a flat response in the extended region. Because of the data extension, one must be careful of interpreting the 3-D data surface beyond the ends of the actual data as indicated in the table.

For the YMT migration of data, a subtraction of a background value is useful to enhance the target response as discussed above. The results for the 3-D surfaces for the amplitude of migrated data are shown in Figures 32-35, where in these figures the data migrated to $50 \mathrm{~m}$ were subtracted from the rest of the migrated data. Figure 32 shows the original data migrated to the surface of the earth with the background subtracted. Comparing Figures 31 and 32 shows that the data migrated down to the earth's surface tend to have a more pronounced null/trough associated with the tunnel. The differenced, migrated data down to a depth of $20 \mathrm{~m}$ are shown in Figure 33. The null/trough associated with the tunnel is still evident and is more clear than in the original data and data migrated to the surface. In addition, the large response associated with the vegetation fence has nearly disappeared indicative of a shallow scatterer. Figure 34 shows the differenced migrated data to a depth of $30 \mathrm{~m}$. Here null/trough associated with the tunnel is still apparent and the response associated with the vegetation fence has all but vanished. Differenced data migrated to a depth of $40 \mathrm{~m}$ are shown in Figure 35 where now the tunnel signature has essentially vanished. 
Table 1. Location of Data Lines

Nomenclature

West 50 Meters

West 25 Meters

West-Road

East 35 Meters

East 65 Meters

\begin{tabular}{c} 
x-coordinate \\
\hline-50 \\
-25 \\
-6 \\
35 \\
65
\end{tabular}

$\begin{gathered}\text { Range of y-coordinate } \\ \text { Measurements } \\ \text { 50-200 } \\ 50-200 \\ 0-250 \\ 50-235 \\ 50-230\end{gathered}$

y-Location of

Tunnel Crossing

119

132

141

161

176

\section{Summary of the Yucca Mountain Tunnel Results}

As at the Cloud Chamber, the RTR equipment used for the acquisition of EM gradiometer data functioned overall in an acceptable manner. However due to the depth to the target, only $5 \mathrm{kHz}$ data were acquired. A cursory test using $10 \mathrm{kHz}$ showed that the target gave a minimal response as suggested by the modeling effort. For the YMT, efforts were concentrated to obtain reasonably good $5 \mathrm{kHz}$ data. In general this was accomplished.

A power amplifier was used to amplify the signal from RTR's transmitter to inject a reasonable current into the transmitting loop. Unfortunately, the power amplifier was a constant voltage device rather than a more desirable constant current device. Maintaining the tuning to get the maximum current into the loop was a problem that required close monitoring of the input to and output of the amplifier. This led to some post-test corrections to the data to eliminate variations due to small current changes in the transmitting loop. Maintaining a more-or-less constant current was more of a problem at the YMT than at the CC. This may have been because of the larger loop at YMT produced a larger impedance to be driven by the power amplifier.

The data display some spatial variation. The sources of this variability are probably the fact that the gradiometer may not have been completely stationary or level when the data were collected. In addition, there were some old cables on the ground that were removed: however, some that were not readily visible may have remained. The vegetation fences caused large responses along the most eastern line. As with the CC migrated results, the act of migration filters the data and the effects of near surface scatterers diminish as the migration depth increases. The phase of the gradiometer response upon crossing the presumed location of the tunnel behaved as the calculated model data predicted. However, the magnitude data did not show a pronounced characteristic response as predicted by the calculated model data. The precise reason for this remains unknown at this time. In order to sort out any geologic and/or target contributions to the apparent anomalous behavior of the magnitude, a survey should be conducted with the transmitting loop on the opposite side of the tunnel. Time constraints prohibited this additional experiment. 
When the data were migrated in the normal manner, the small null apparently associated with the tunnel disappeared even for shallow migration depths. To enhance this small null, the data migrated to $50 \mathrm{~m}$ deep were subtracted from the normal migrated data to give a differenced migrated data. As was shown from taking the Fourier transform of the differenced migrated results, this differencing in effect allows larger values of the wavevector to contribute to the inverse Fourier transformed results thereby maintaining the null feature to depths of the tunnel. The null/trough feature associated with the tunnel aligns more-or-less along the presumed strike of the tunnel. The data suggest that the tunnel runs from coordinates W-to-E $-50 \mathrm{~m}, \mathrm{~N}$-to-S $140 \mathrm{~m}$ to W-to-E $65 \mathrm{~m}, \mathrm{~N}$-to-S 150 $\mathrm{m}$ which is not exactly at the presumed location of the tunnel. Without further field testing, this discrepancy cannot be resolved.

The migration method removes the effects of the responses from shallow scatterers while retaining the responses from the deeper targets. The location and approximate depth of the YMT are apparent in the migrated data. At the general location of the survey, the tunnel contains small rooms off to the northern side of the main tunnel. It is not known at the present time if these small rooms are indeed under the area surveyed.

\section{CONCLUDING REMARKS}

The RTR gradiometer was a laboratory grade (not prototype) instrument and in general performed satisfactorily. The main deployment strategy tested was an off-set, fixed transmitting VMD and a roving $5 \mathrm{~m}$ gradiometer receiver package. The RTR transmitter driving the power amplifier that drove current into the $\mathrm{VMD}$, the gradiometer receiver, and the data acquisition computer were all connected by fiber optic cables for signal transmission. The gradiometer approach with a $5 \mathrm{~m}$ separation between the two receivers was able to detect the Yucca Mountain tunnel up to depths of approximately $30 \mathrm{~m}$. The shallow Cloud Chamber target presented no problem for detection. Both of these targets contained a significant amount of electrically conducting material for the EM induction scattering. In both cases, however, the field data did not exactly match the calculated model data. Precise reasons for the discrepancy are not clear at present. Further modeling and field testing are required to resolve the discrepancy. However, the EM gradiometer approach to locate and characterize underground targets seems to be a viable approach.

The EM wave migration method used in the analysis of the data filtered the responses from near-surface scatterers while retaining the response of the deeper targets. At the Cloud Chamber site there was a significant amount of cabling laying on the ground over portions of the survey area and at the Yucca Mountain Tunnel there were some surface fences. In both instances, the effects of these surface scatterers were mitigated by the migration process while retaining the response from the desired target. The migration method is quite fast and can easily be implemented on a field computer. The Fourier transforms used in the method utilized available FFT algorithms such as available using the MATLAB® software. 
The migrated or extrapolated field (in this case the gradiometer response) provides the known fields in the interior of the earth so that an integral equation can be solved for the conductivity structure (Bartel, 1994). The wave migration used here is entirely equivalent to the Green's theorem integral formulation to obtain the migrated or extrapolated fields used by Bartel, 1994. Two-dimensional conductivity "slices" through the earth can be obtained on PC-type computers (Bartel, 1994). However, for 3-D conductivity structures a larger memory, faster computer would be necessary. One may be able to solve the 3-D problem on new, high-end PC's. In addition, the migrated fields can be used as a starting model for more sophisticated inversion algorithms that require computer work stations or mainframe computers (Newman, private comm.). A reasonable starting model would reduce the computer time to produce an electrical conductivity model for these inversions.

GEOPHEX acquired EM data using their GEM-2 system over the Cloud Chamber and the Yucca Mountain Tunnel (Cogbill, private comm.). For the shallow Cloud Chamber target and the associated line-of-sight pipe (Won, et al., 1996), the GEM-2 data clearly detected these targets. However, for the deeper Yucca Mountain Tunnel the GEM-2 data did not show any recognizable response from the tunnel in agreement with model calculations (Alumbaugh, private comm.). The GEM-2 system was developed for the mapping and characterization of shallow targets such as for environmental concerns (Won, private comm.). In addition, SNL sponsored an ellipticity method survey for imaging the YMT in a separate effort (Sternberg and Poulton, 1996). The results of this limited survey showed that this method can also detect the YMT. However, the numbers of survey lines that crossed the tunnel were limited so that the delineation of the tunnel was not as clear as with EM gradiometer survey discussed in this report. If the magnetic field data obtained in the ellipticity survey are used to determine a field gradient (not discussed in this report), then the tunnel is more apparent in this EM gradient data than the ellipticity data.

Despite the success of the EM gradiometer hardware tested, there were some hardware issues that need to be addressed. These include: (1) accurate gain and/attenuator changes to yield better data quality, (2) better method of power amplification to maintain a constant current, (3) broader band receivers so that tuning capacitors do not need to be switched to "tune" the coils that would allow for more rapid data collection at arbitrary frequencies, and (4) the connection of the "system" utilizing fiber optic cables made field operations cumbersome. When the transmitter and receivers are highly tuned, small changes in the inductive coupling to the earth can detune the coils and possibly give false variations in the received signal. For the data collected at NTS the detuning effect probably did not affect the data. The equipment as built by RTR utilized long, small diameter ferrite core coils for both their transmitter and receivers. Since space is not a major problem but weight is a problem, use of air core coils should be investigated. It is noteworthy that the GEM-2 system uses air core coils. Air core coils are inherently broad band and would not be significantly affected by the detuning effect of the surrounding geologic structure. Replacement of the fiber optic cables with a radiofrequency link would make the system easier to deploy in the field. 
Finally, other gradiometer deployment strategies need to be investigated. Computer modeling (not discussed here) of a transmitting antenna located at the midpoint of a threeaxis gradiometer is a system that can detect underground targets from a low flying airborne platform. Further modeling and testing of this configuration appear warranted.

\section{REFERENCES}

Bartel, L. C., 1992, Application of wave migration to borehole vertical electric source EM data: Expanded abstracts 62nd Int'1. Ann. Mtg. Soc. of Explor. Geophysicists, New Orleans, LA, Oct. 25-29, 506-510.

1994, Integral wave-migration method applied to electromagnetic data:

Expanded abstracts 64th Int'l. Ann. Mtg. Soc. Explor. Geophysicists Los Angeles, CA Oct. 23-28, 361-364.

Benchmark Study, 1994, Technical capabilities, research efforts, and recommendations for underground target detection using geophysical techniques: U.S. Dept of Energy Report, DOE/NN/0001, 146 pp.

Claerbout, J. F., 1971, Toward a unified theory of reflector mapping: Geophysics, 36, 467-481.

Cress, D. H., Bartel, L. C., Brock, B., Alumbaugh, D. L., and Newman, G. A., 1996, Detection of subsurface structures using electromagnetic induction techniques: Sandia National Laboratories Report, to be published.

Electromagnetic methods in applied geophysics, 2, 1987, ed. M. N. Nabighian, Soc. Explor. Geophys.

Freeman, L. E. and Cogbill, A. C., 1995, A catalog of underground detection technology test sites: Nonproliferation and National Security Office of R and D, Rpt No. $\mathrm{DOE} / \mathrm{NN} / 0003$.

Goodman, J. W., 1968, Introduction to Fourier Optics: McGraw-Hill.

Lowenthal, D., Lu, L., Roberson, R., and Sherwood, J. W. C., 1976, The wave equation applied to migration: Geophys. Prosp., 24, 380-399.

Newman, G. A., Hohmann, G. W., and Anderson, W. L., 1986, Transient electromagnetic responses of a three dimensional body in a layered earth: Geophysics, 51, 16081627. 
Sasaki, Y., 1989, Application of phase-shift migration to magnetotelluric data: Exp. Abs. 59th Int'l. Ann. Mtg. Soc. Explor. Geophysicists, Dallas, TX, Oct 29-Nov.2, 165-167.

Schneider, W. A., 1978, Integral formulation for migration in two and three dimensions, Geophysics, 43, 49-76.

Sternberg, B. K. and Poulton, M. M., 1996, LASI ellipticity survey at the Nevada Test Site for Sandia National Laboratories: Laboratory for Advanced Subsurface Imaging, Dept. of Mining and Geological Engr., U. of Arizona, Tucson, AZ, Final Report Sandia Contract \# AS-2042-0144.

Stolarczyk, L. G., 1991, Radio imaging in seam waveguides: in Investigations in Geophysics No. 5, Soc. Explor. Geophysics, Geotechnical and Environmental Geophysics, 3, ed. S. H. Ward, 187-209.

U. S. Department of the Army Belvoir Research, Development, and Engineering Center, 1993, Tunnel neutralization team (TNT) support program, CALOP3 Final Report.

Ward, S. H. and Hohmann, G. W., 1987, Electromagnetic theory for geophysical applications: in Investigations in Geophysics No. 3, Soc. Explor. Geophysics, Electromagnetic Methods in Applied Geophysics, 1, Theory, ed. M. N. Nabighian, 136.

Won, I. J., Keiswetter, D. A., Fields, R. A., and Sutton, L. C., 1996, GEM-2 a new multifrequency electromagnetic sensor: J. of Envir. and Engr. Geophysics, 1, 129137. 


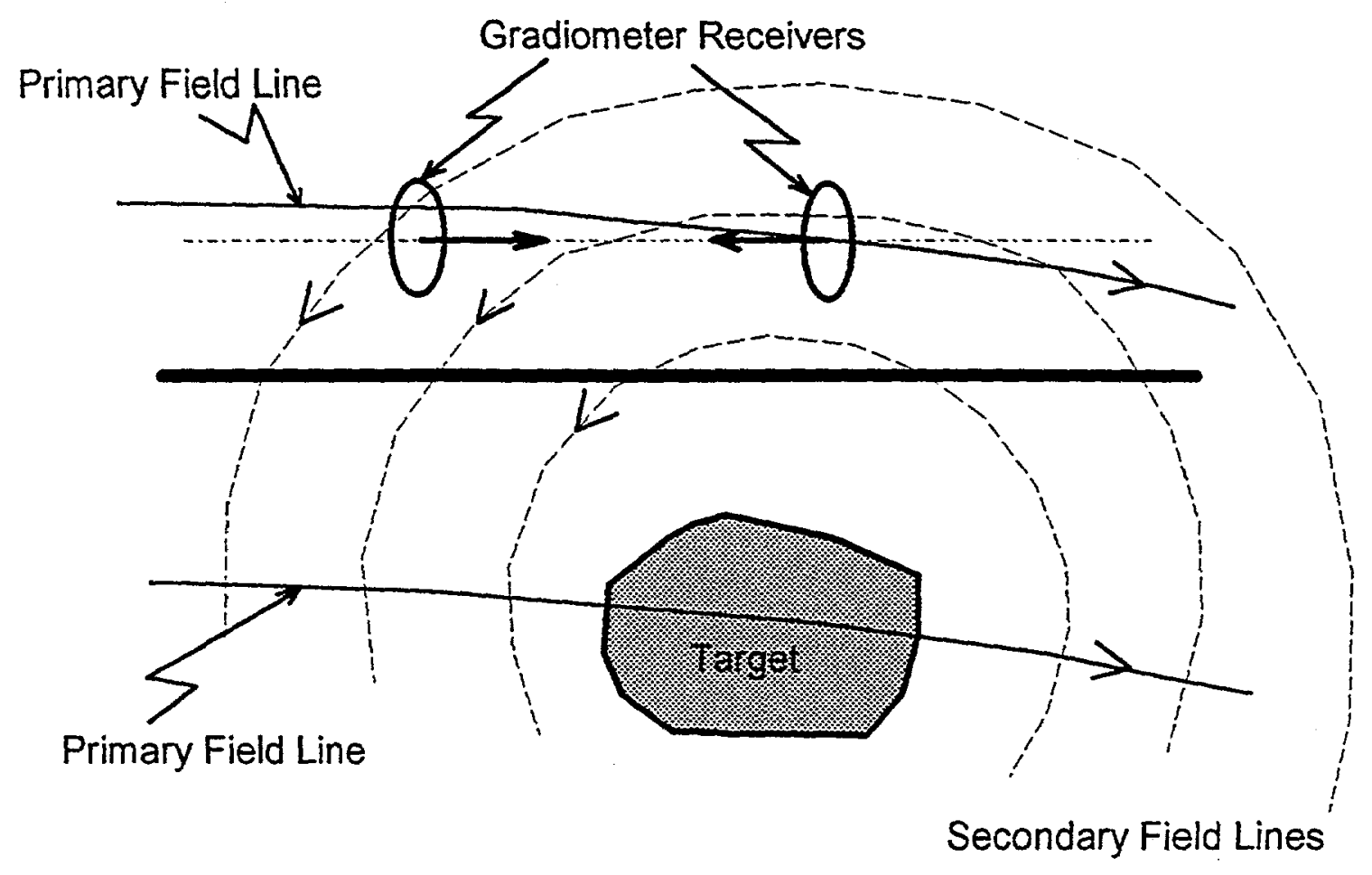

Fig. 1 Schematic of the gradiometer concept. 


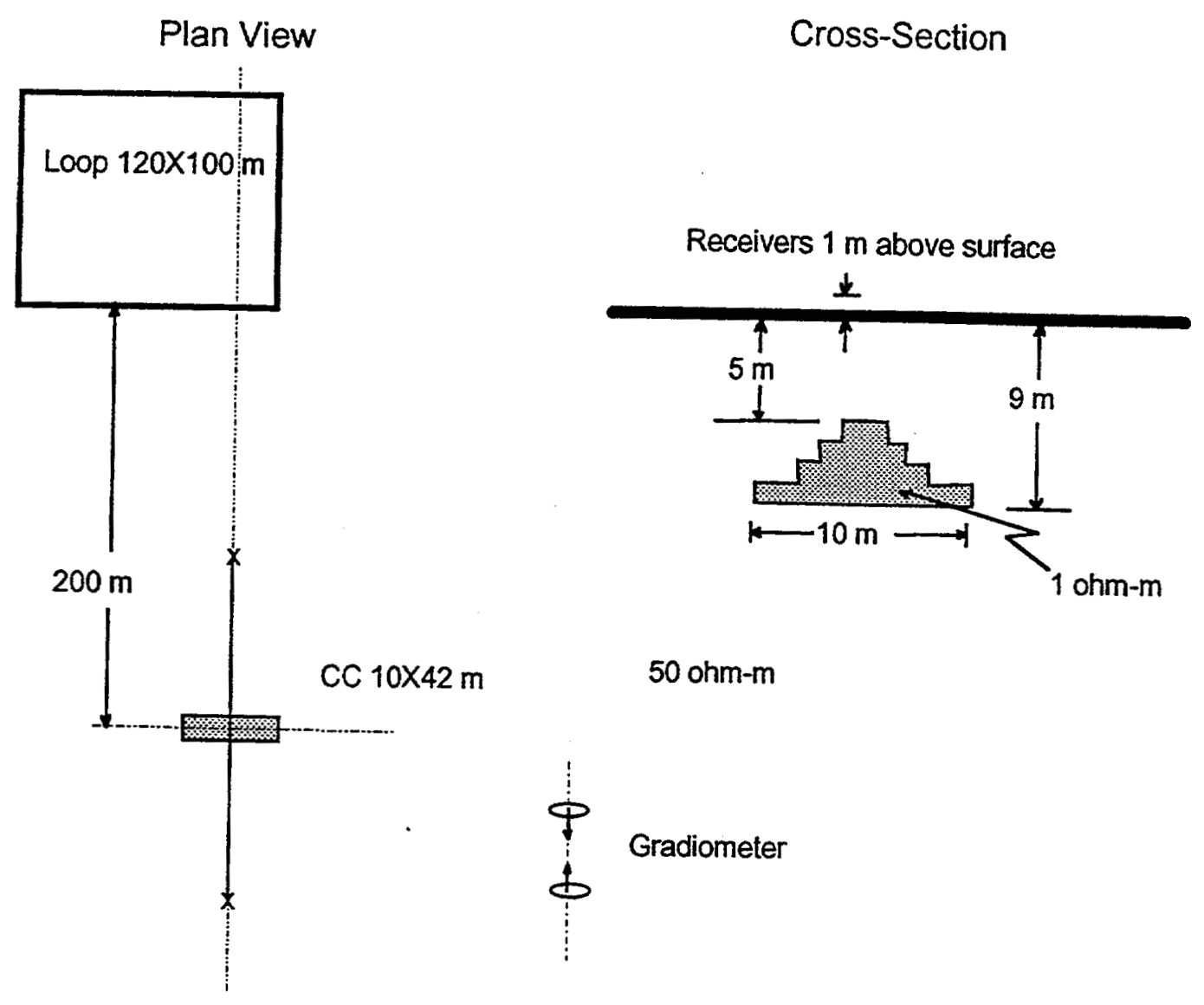

CL \& Off-set Survey Lines

Fig. 2 Model for Cloud Chamber model simulations. 


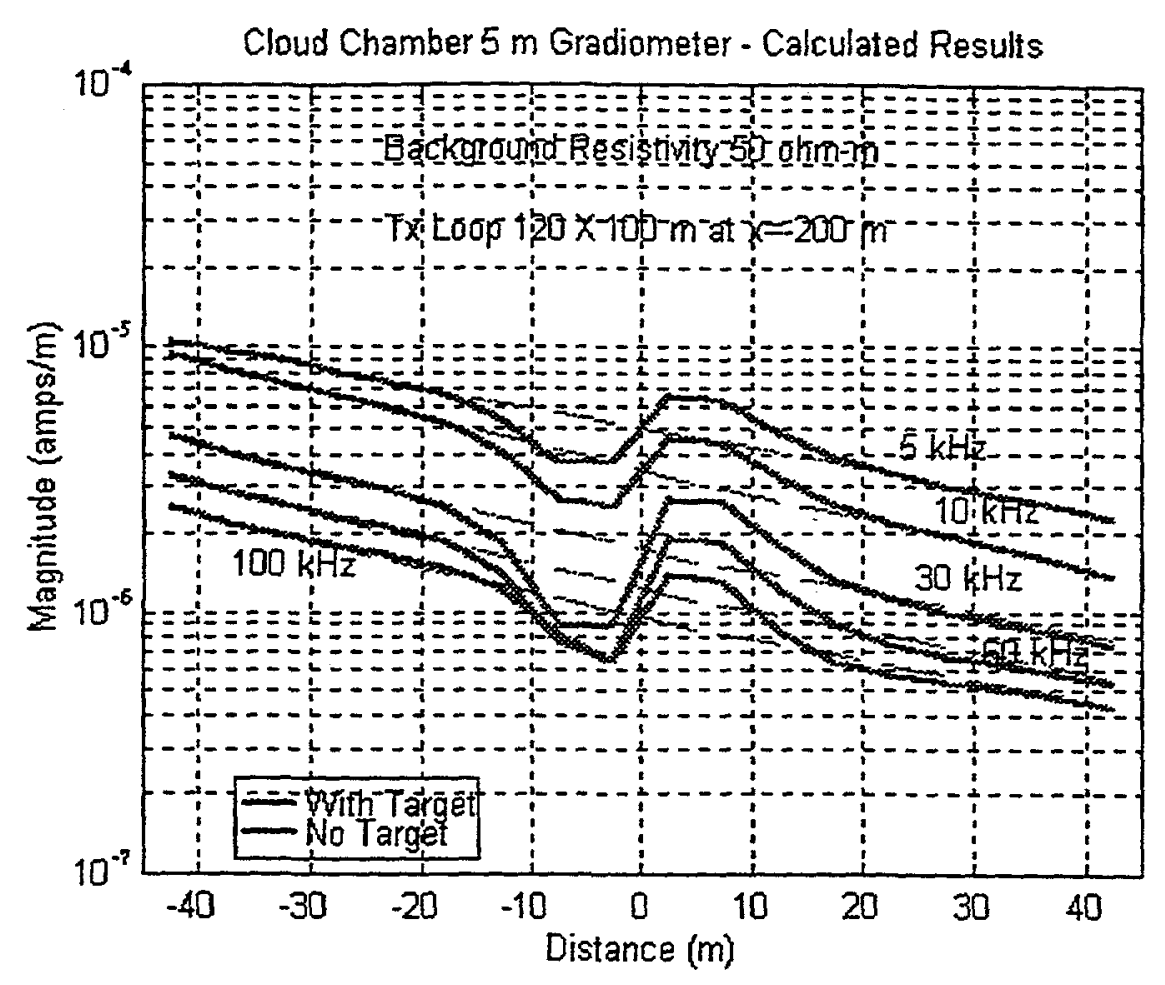

Fig. 3 Calculated $5 \mathrm{~m} \mathrm{EM}$ gradiometer magnitude response. Shown are the gradient response with the target in place (solid line) and without the target (dashed line). Note that the results have not been divided by the receiver separation.

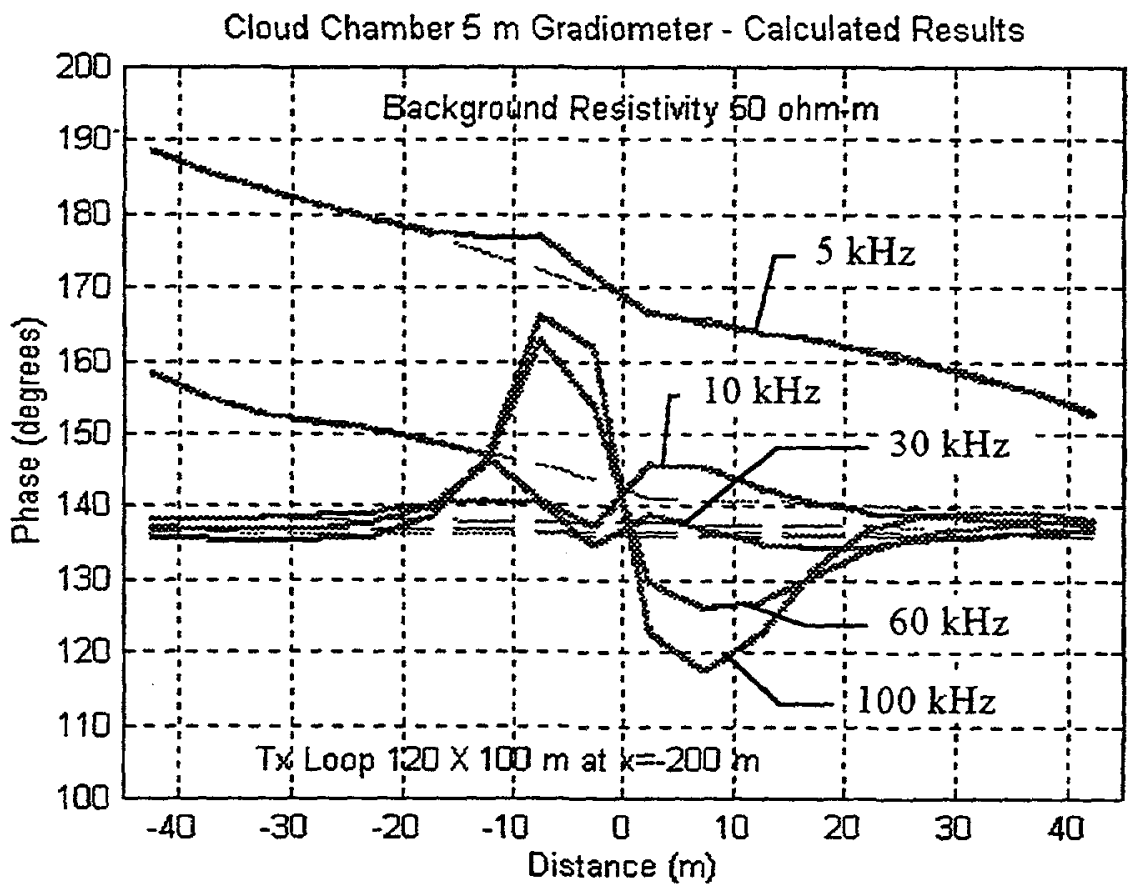

Fig. 4 Calculated $5 \mathrm{~m}$ EM gradiometer phase response. 


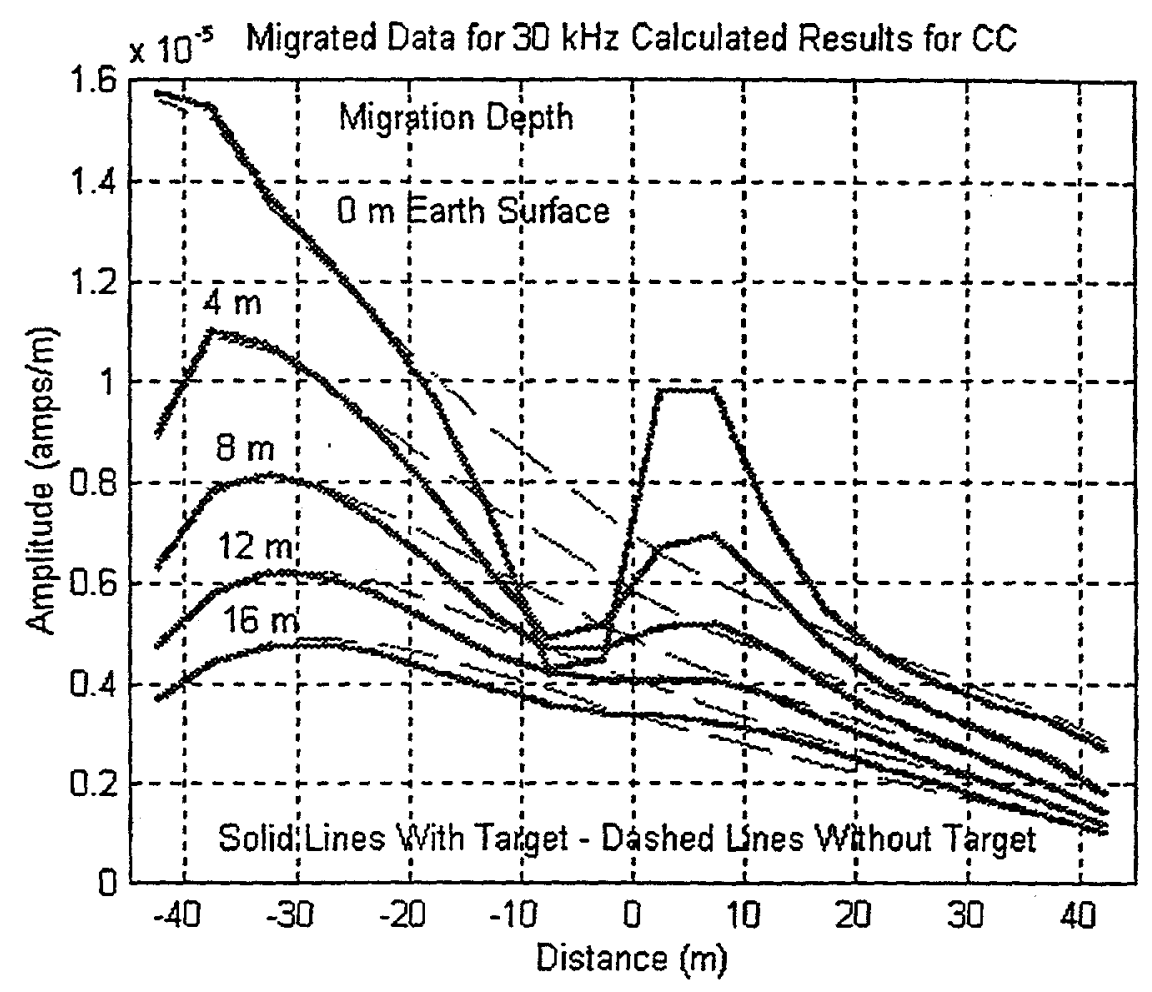

Fig. 5 Results of migrating the $30 \mathrm{kHz}$ calculated $5 \mathrm{~m}$ EM gradiometer data to various depths. The results at $0 \mathrm{~m}$ are the data migrated from $1 \mathrm{~m}$ above the earth's surface.

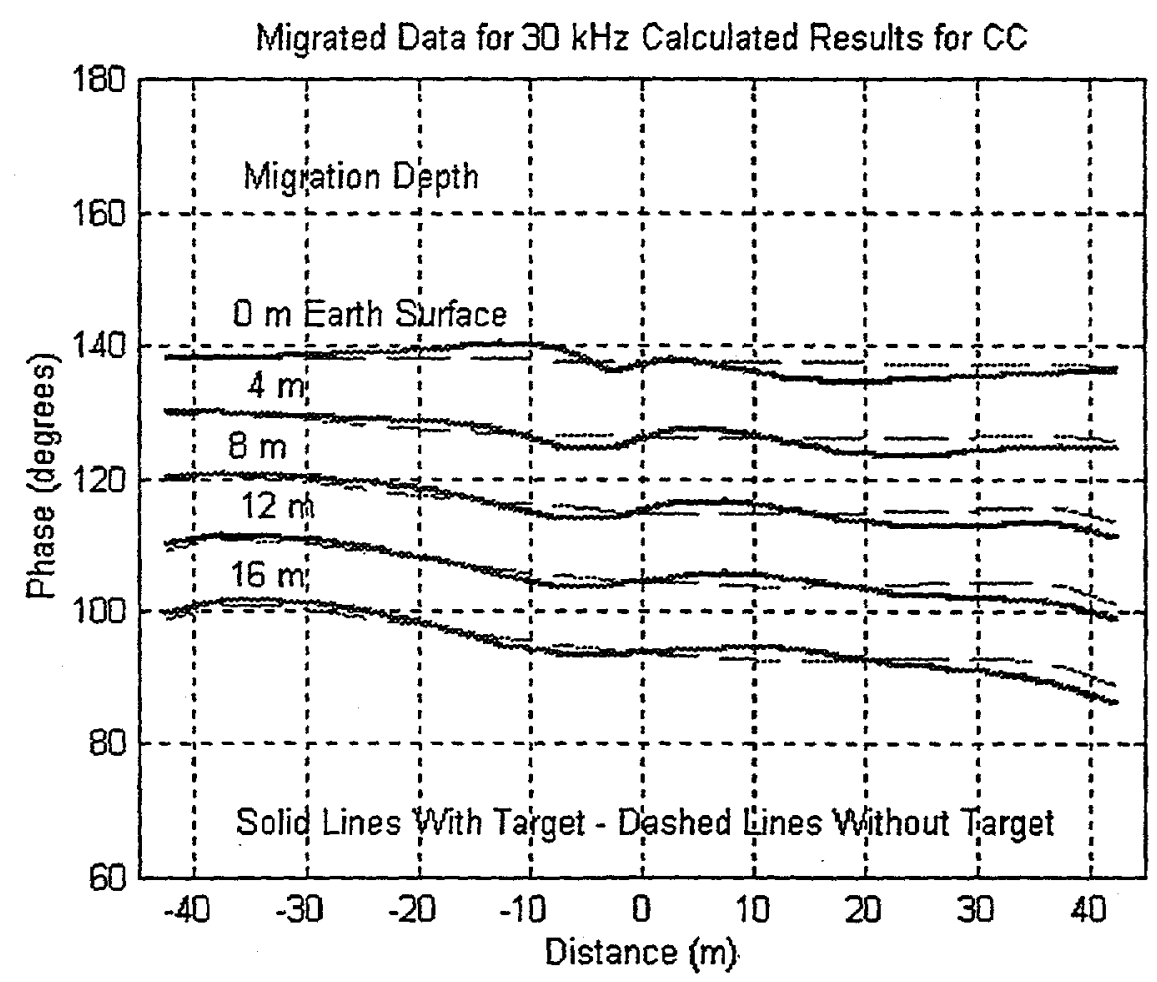

Fig. 6 Phase of migrated $30 \mathrm{kHz}$ calculated results for the Cloud Chamber. 


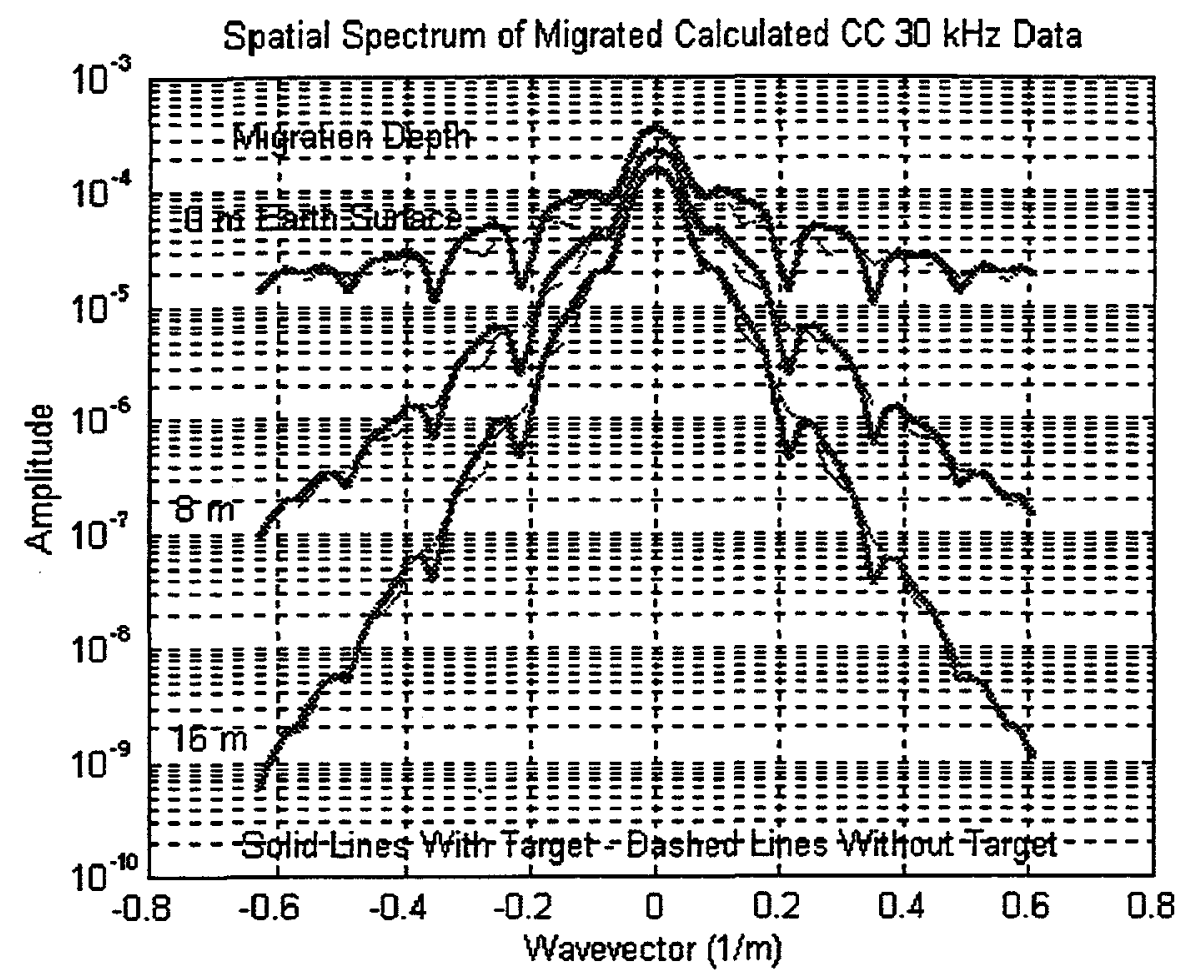

Fig. 7 Spatial spectrum for migrated $30 \mathrm{kHz}$ calculated $5 \mathrm{~m}$ gradiometer results. Solid lines show results with the target in place and dashed line without the target. 


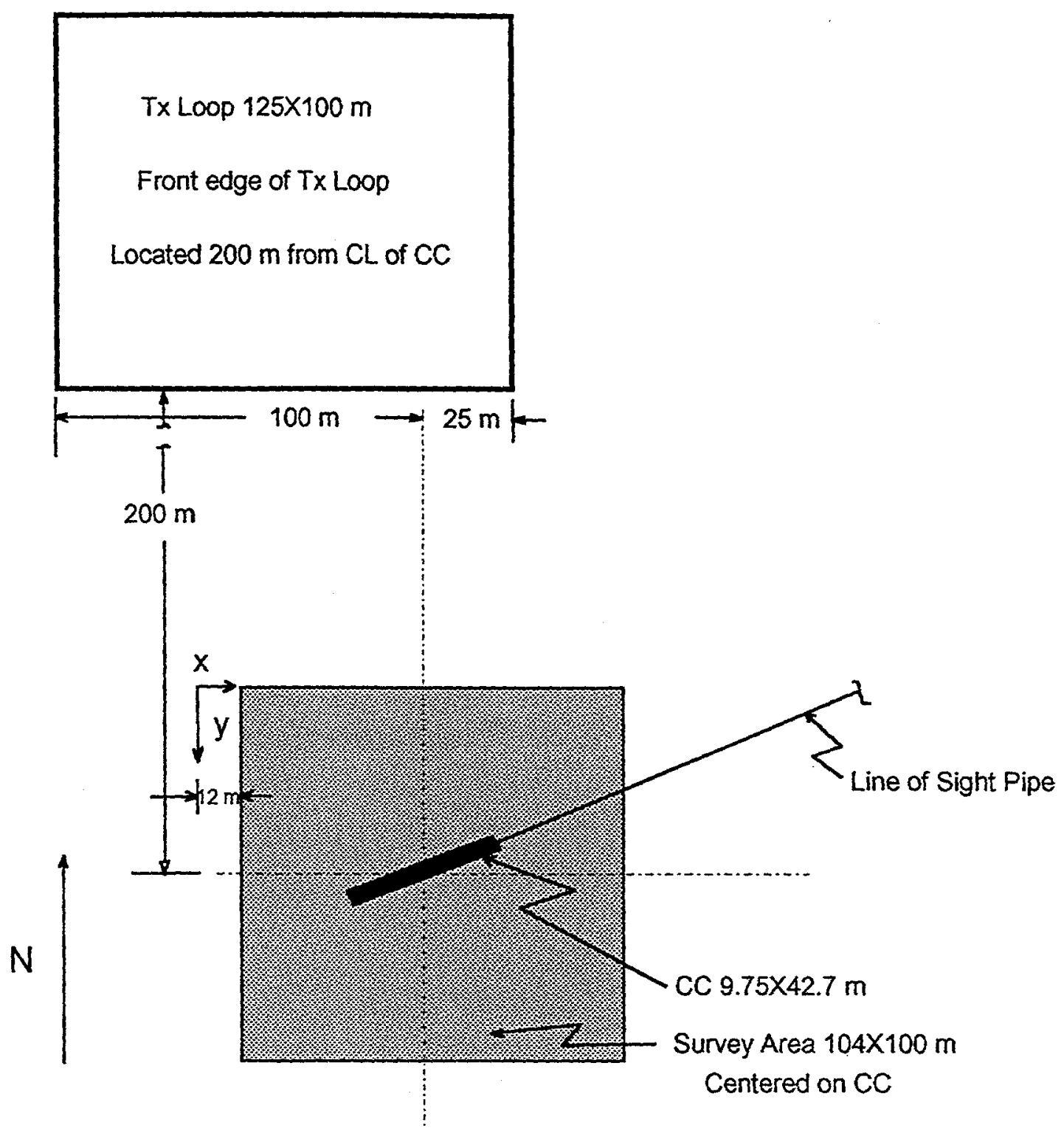

Survey Lines $8 \mathrm{~m}$ Spacing Running N-S Direction $100 \mathrm{~m}$ Long

Fig. 8 Survey for the Cloud Chamber. 


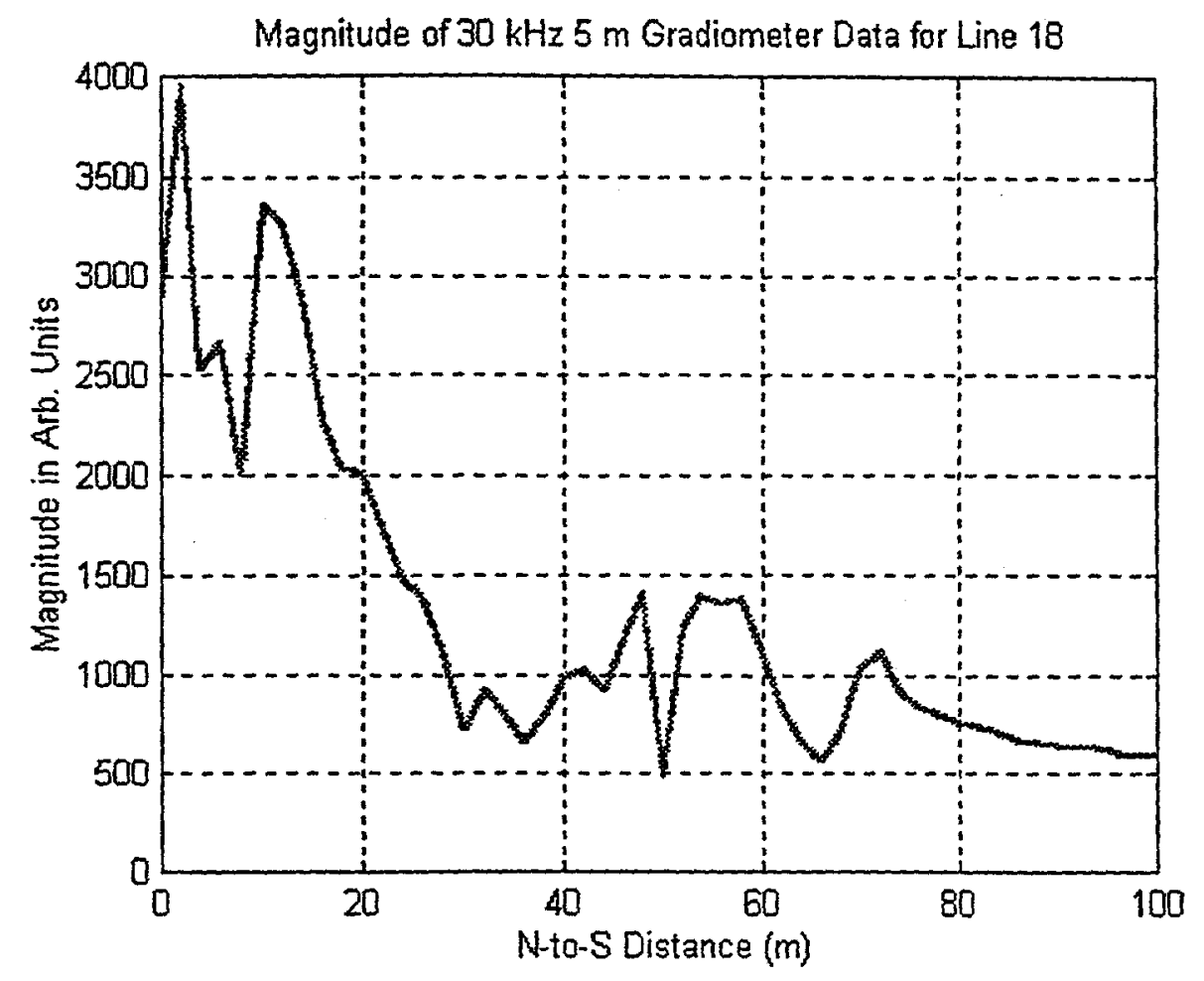

Fig. 9 Magnitude of $30 \mathrm{kHz} 5 \mathrm{~m}$ gradiometer data for Line 18. The magnitude is in arbitrary units.

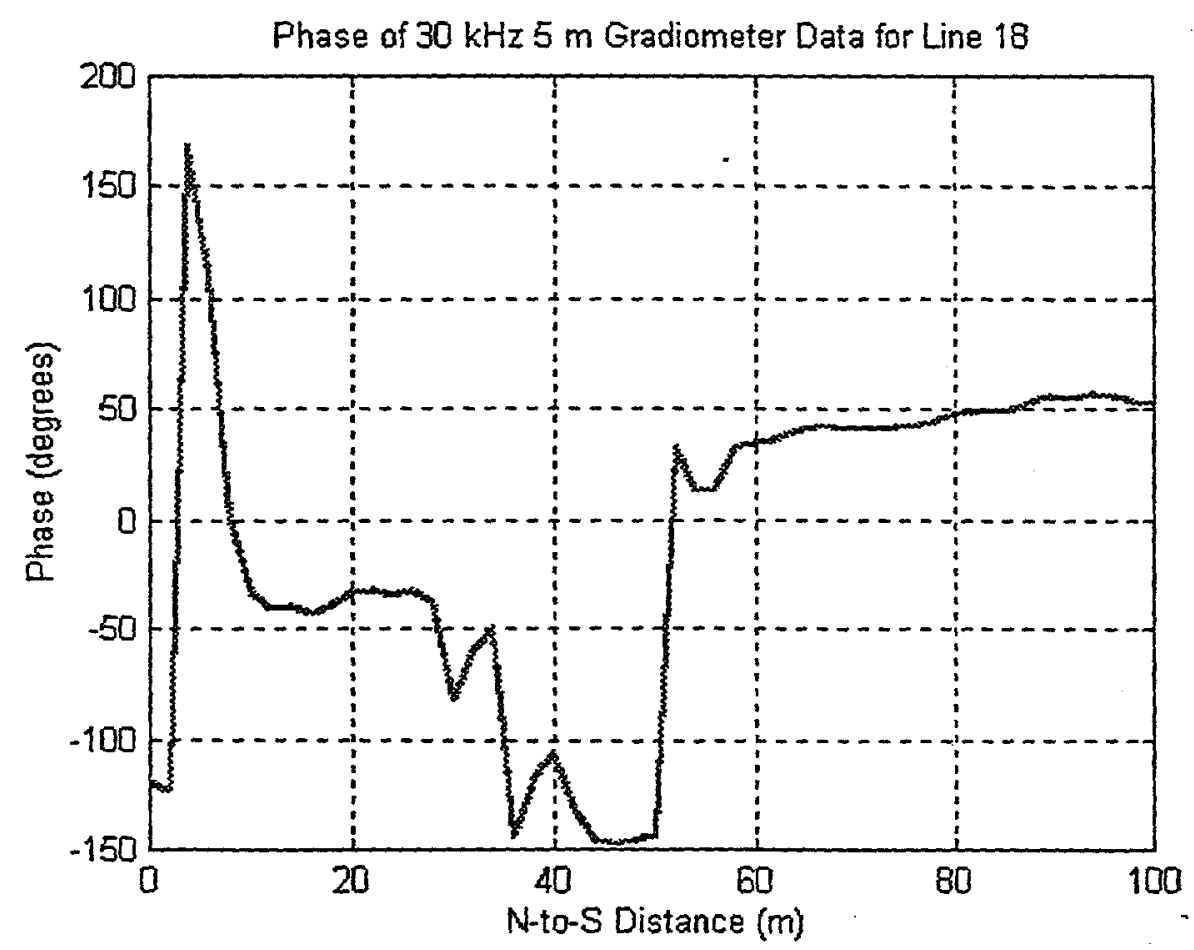

Fig. 10 Phase results for the $30 \mathrm{kHz} 5 \mathrm{~m}$ gradiometer data for Line 18. 


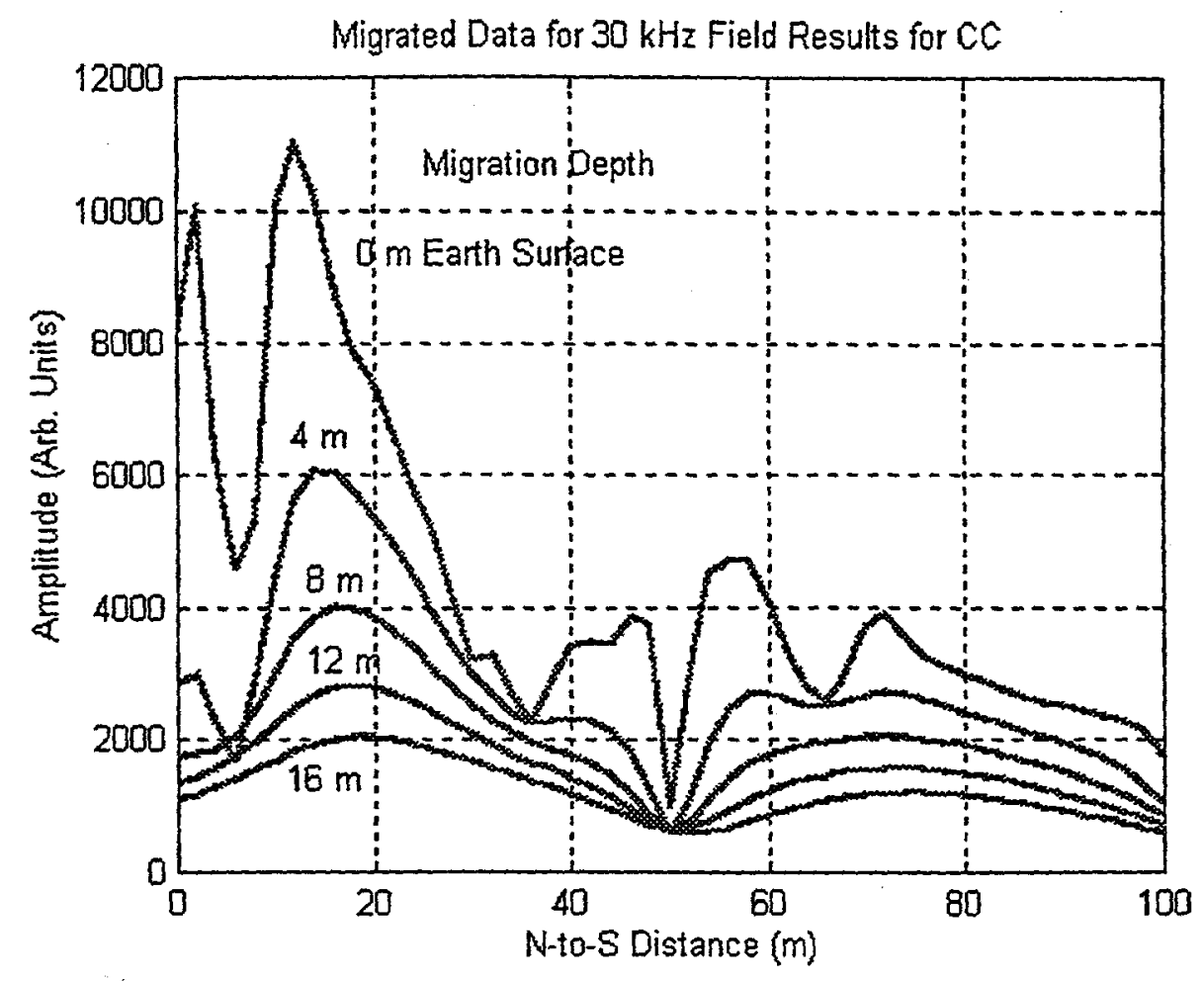

Fig. 11 Magnitude of migrated $30 \mathrm{kHz}$ data for Line 18 .

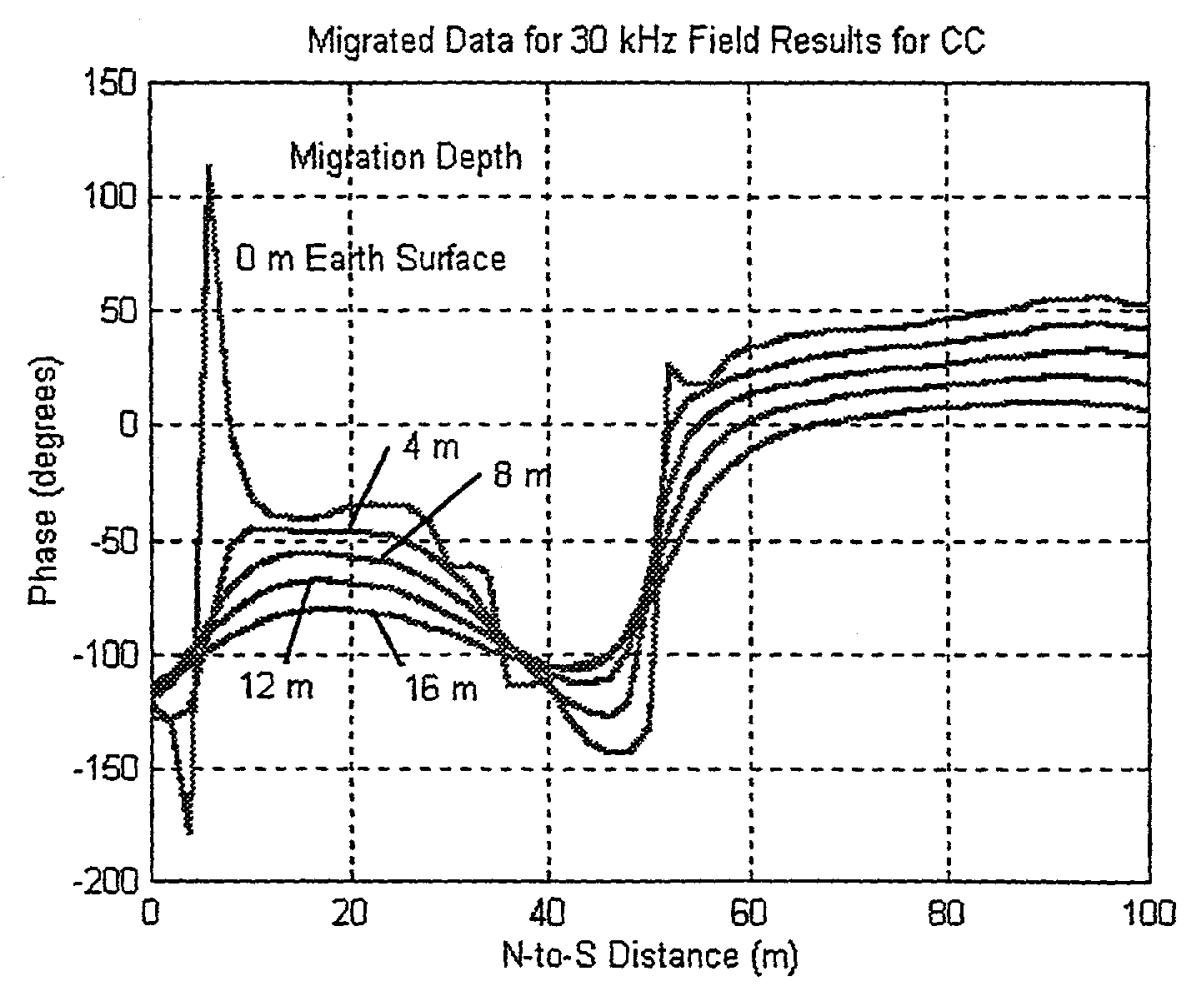

Fig. 12 Phase of migrated $30 \mathrm{kHz}$ data for Line 18. 


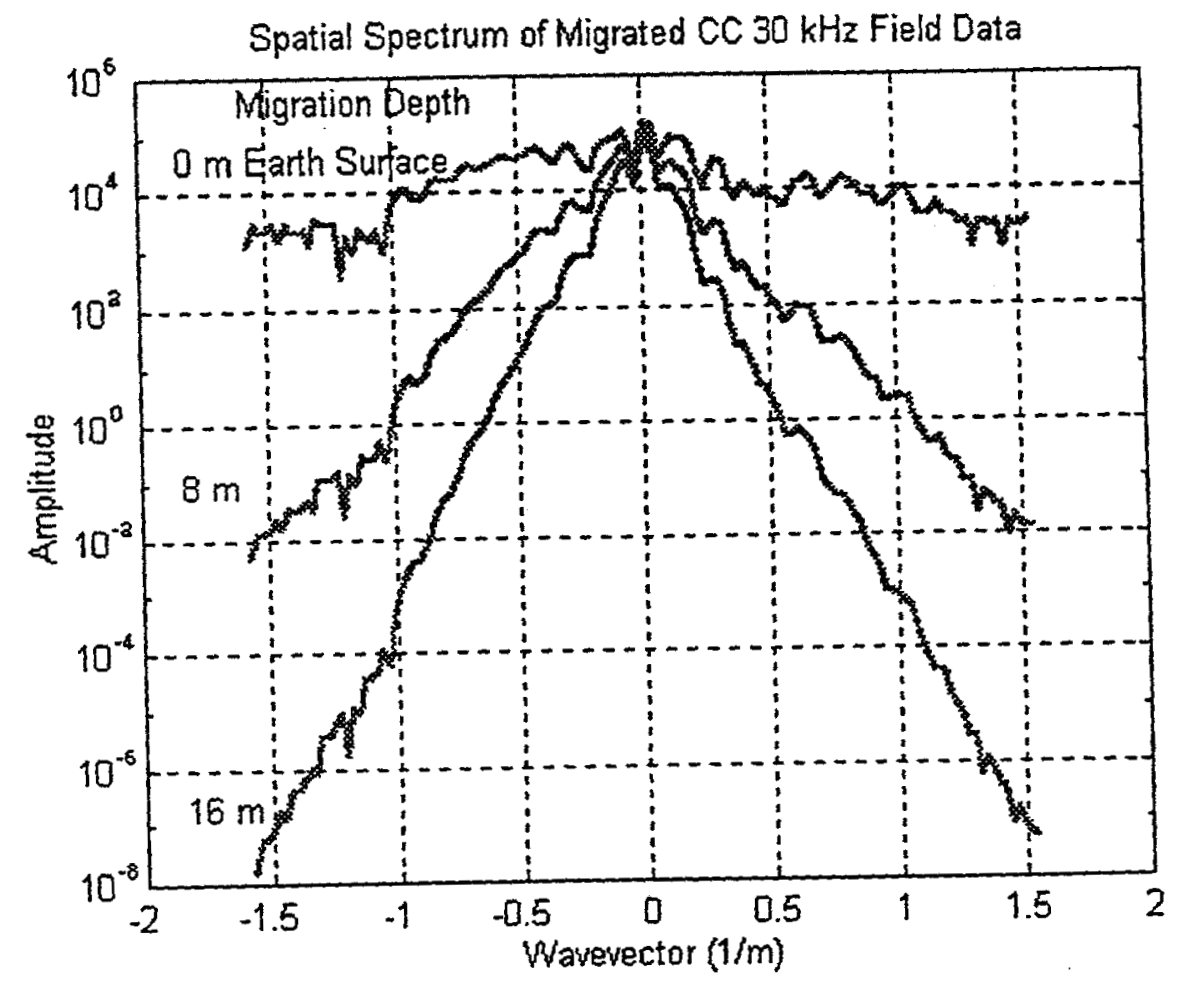

Fig 13. Migrated $30 \mathrm{kHz}$ data for Line 18 in wavevector space.

3-D Surface of Original CC Amplitude Data

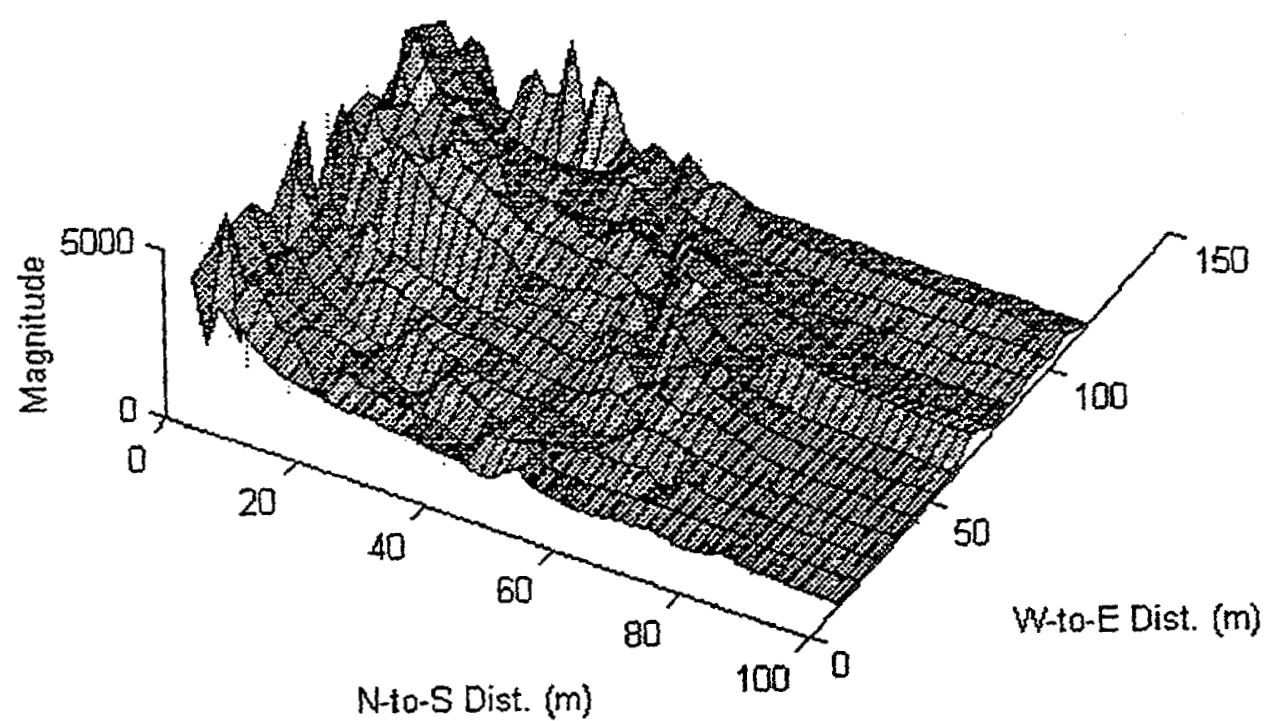

Fig. 14 Amplitude 3-D surface for Cloud Chamber data at $30 \mathrm{kHz}$. 


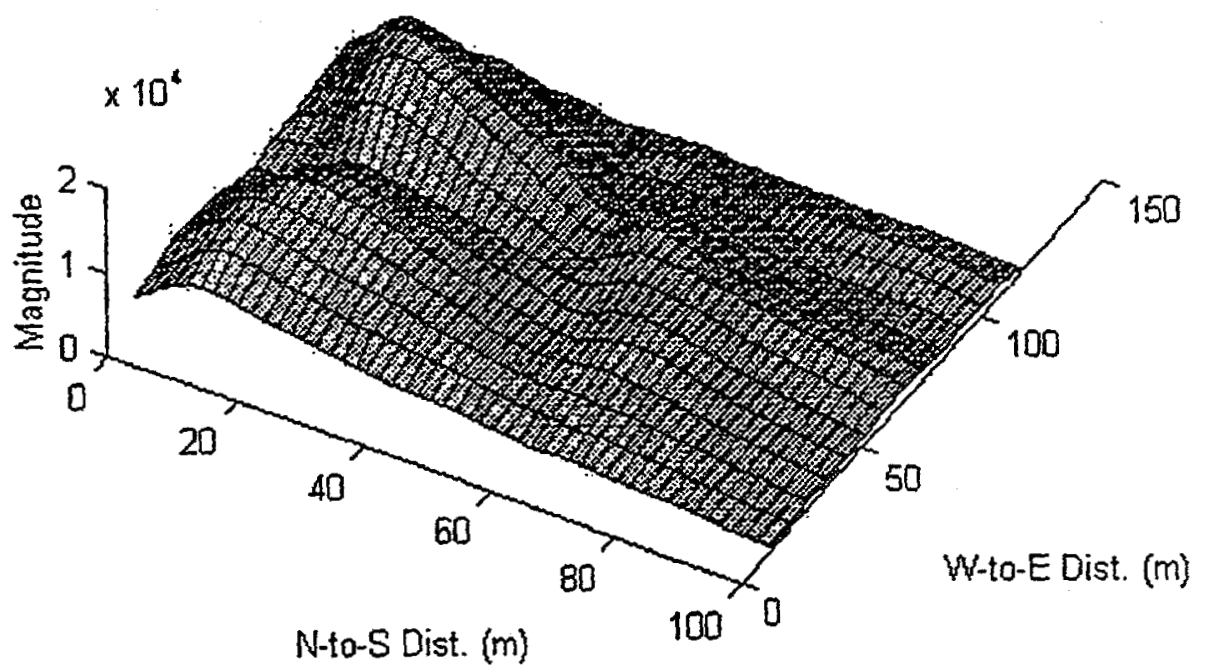

Fig. 15 Amplitude surface for Cloud Chamber data at $30 \mathrm{kHz}$ migrated to a depth of $8 \mathrm{~m}$. Amplitude is in arbitrary units.

3-D Surface of CC Data Migrated to a Depth of $16 \mathrm{~m}$

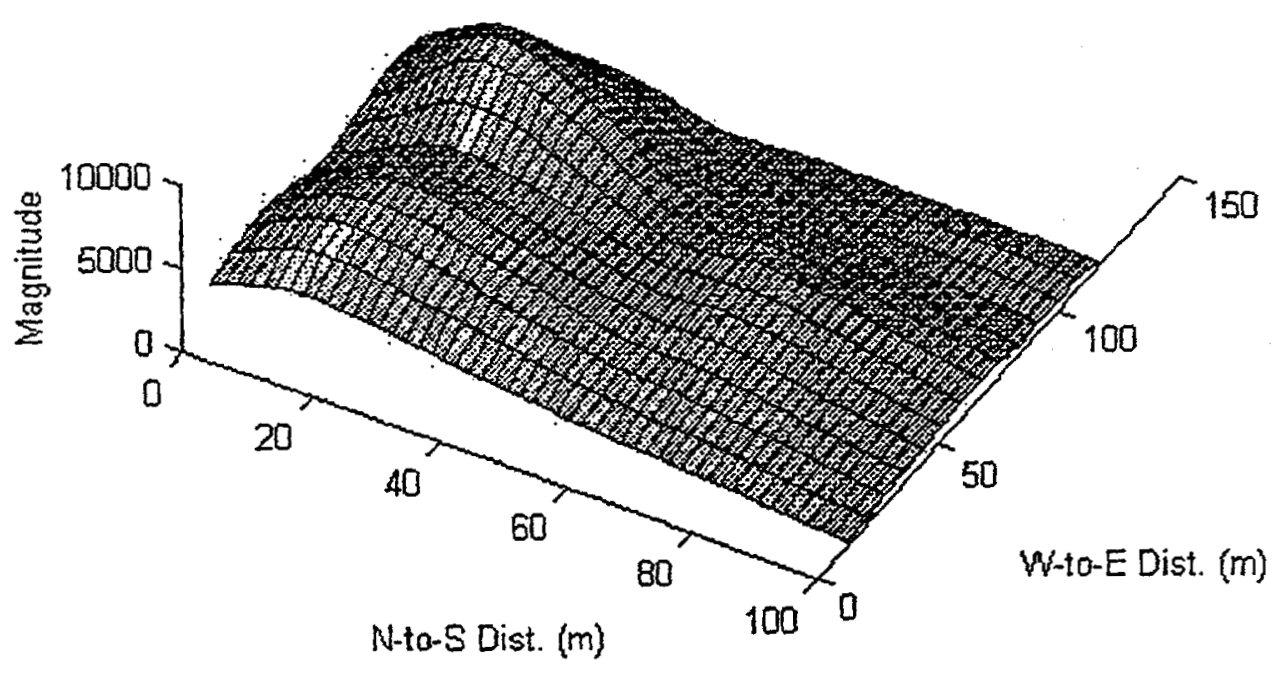

Fig. 16 Amplitude surface for Cloud Chamber data at $30 \mathrm{kHz}$ migrated to a depth of $16 \mathrm{~m}$. Amplitude is in arbitrary units. 
Plan View

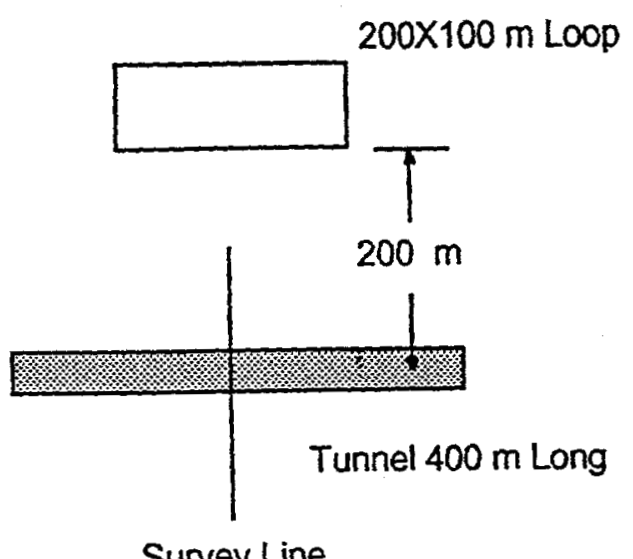

Survey Line
Cross-Section

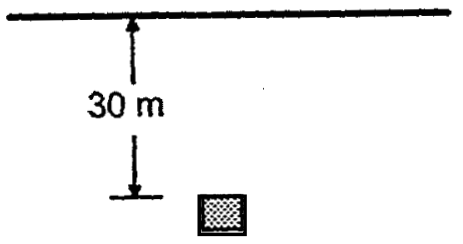

Tunnel $4 \times 4 \mathrm{~m}$ 1 ohm-m

500 ohm-m Background

Receivers $1 \mathrm{~m}$ above surface

Fig. 17 Yucca Mountain Tunnel model.

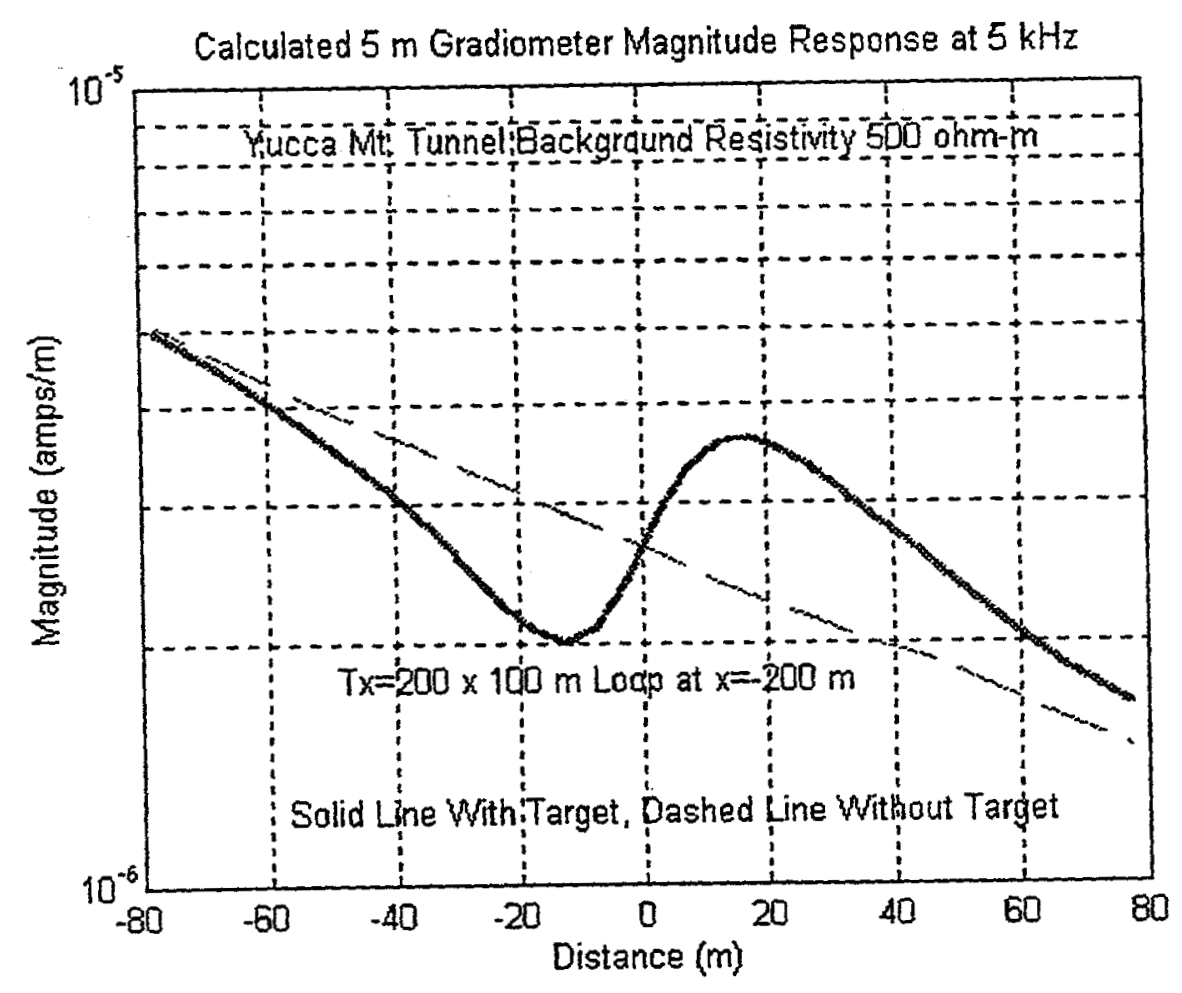

Fig. 18 Calculated magnitude of the $5 \mathrm{~m}$ gradiometer response at $5 \mathrm{kHz}$. Solid line with target in place and the dashed line with no target. 


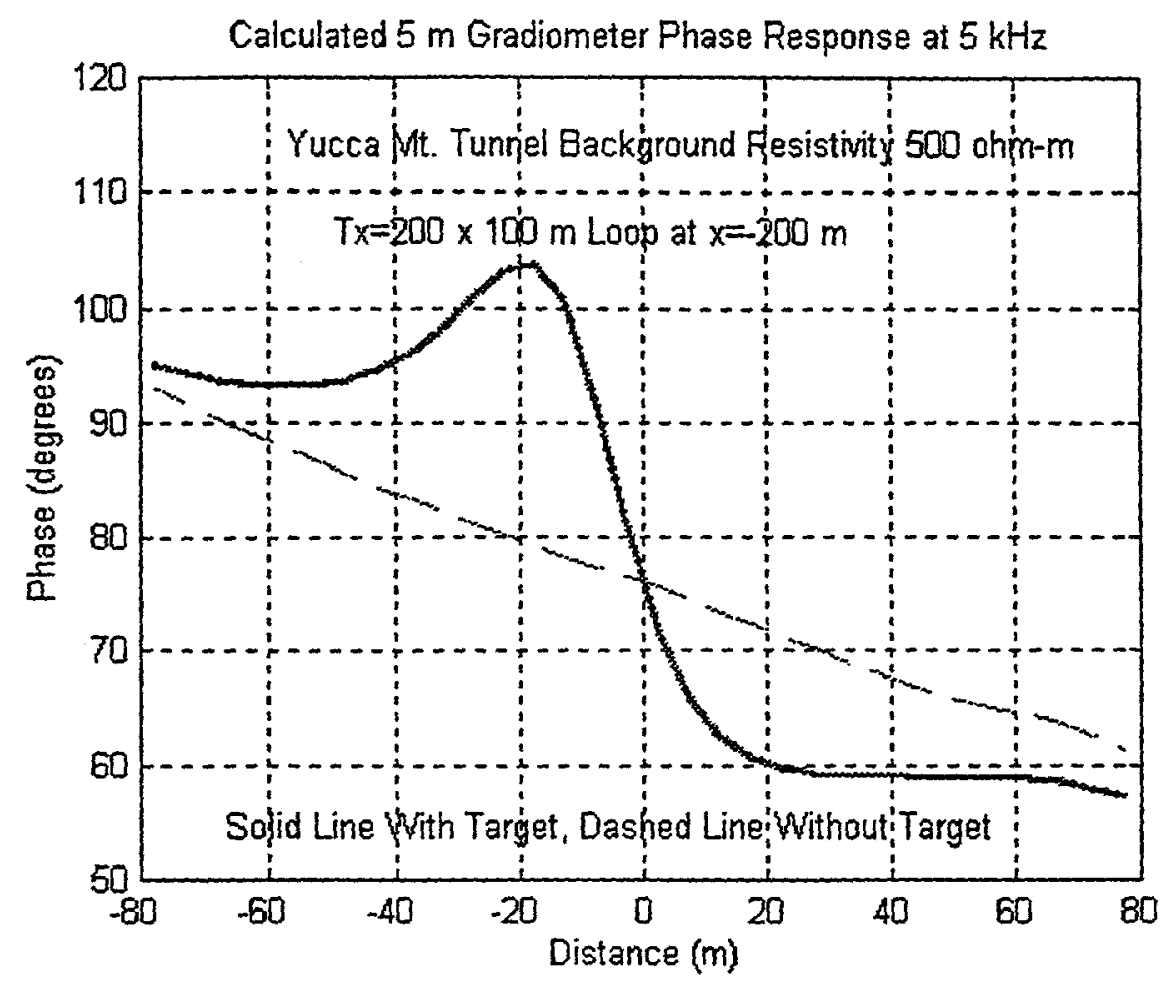

Fig. 19 Calculated phase response for $5 \mathrm{~m}$ gradiometer at $5 \mathrm{kHz}$. Solid line with target in place and dashed line with no target.

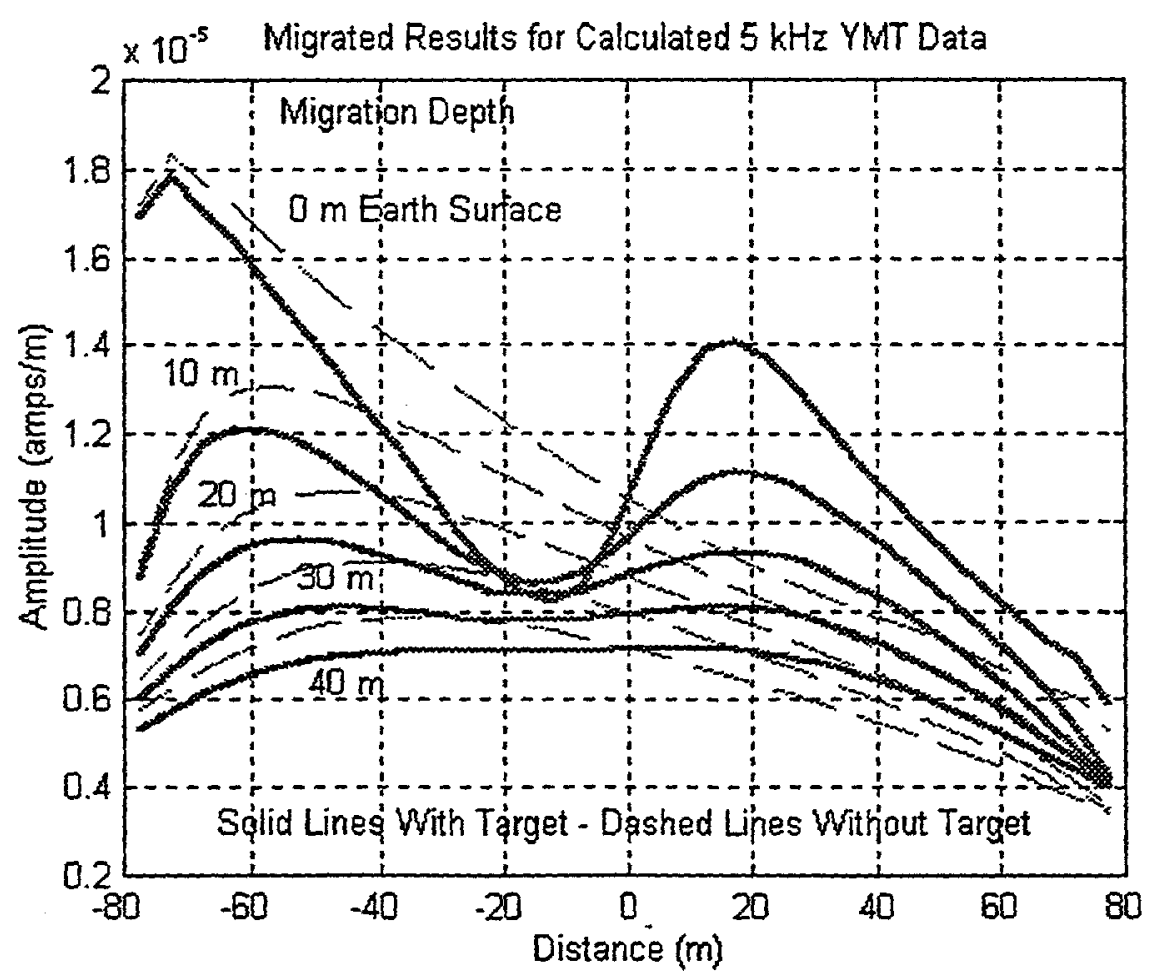

Fig. 20 Amplitude of migrated results for calculated $5 \mathrm{kHz}$ YMT data. 


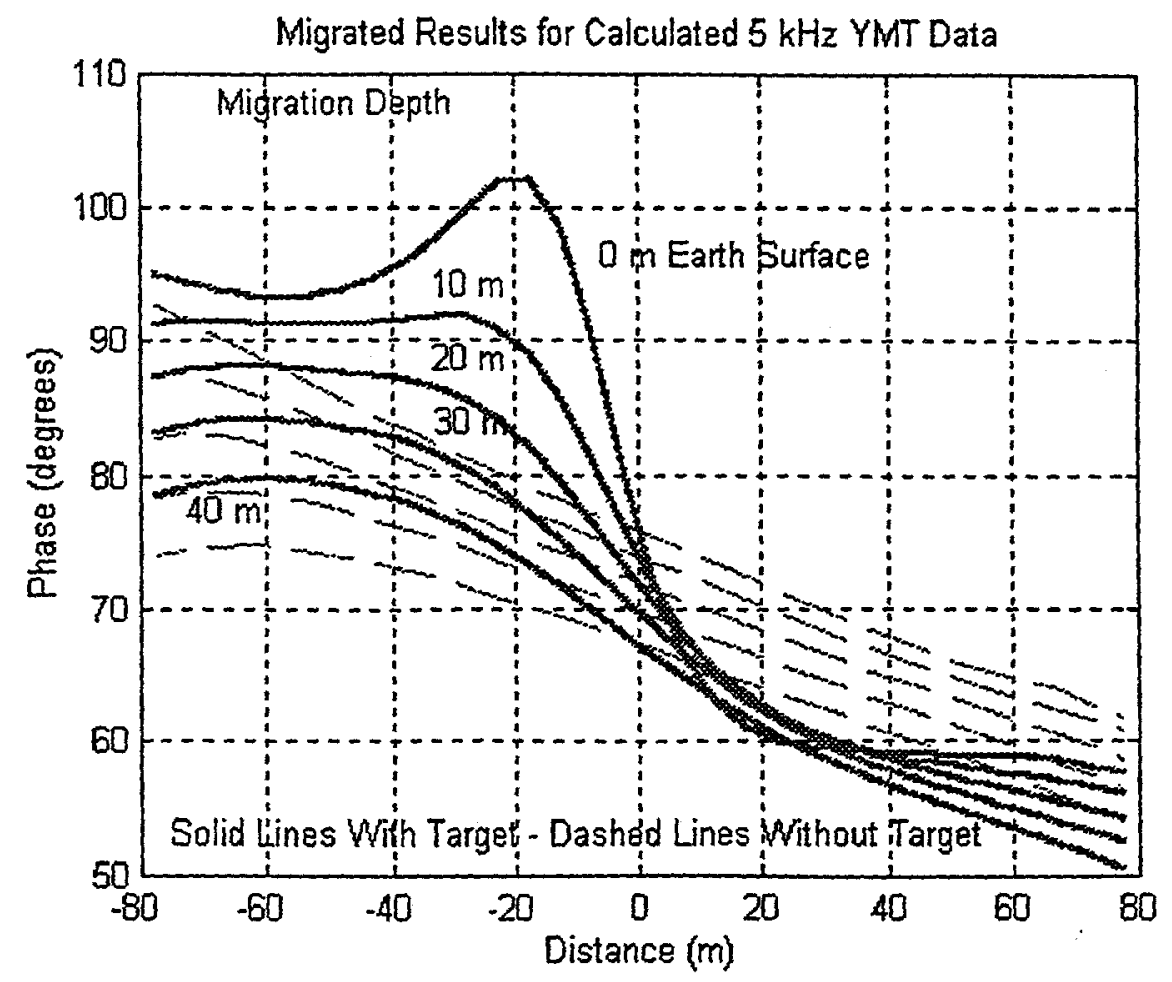

Fig. 21 Phase of migrated results for calculated $5 \mathrm{kHz}$ YMT data.

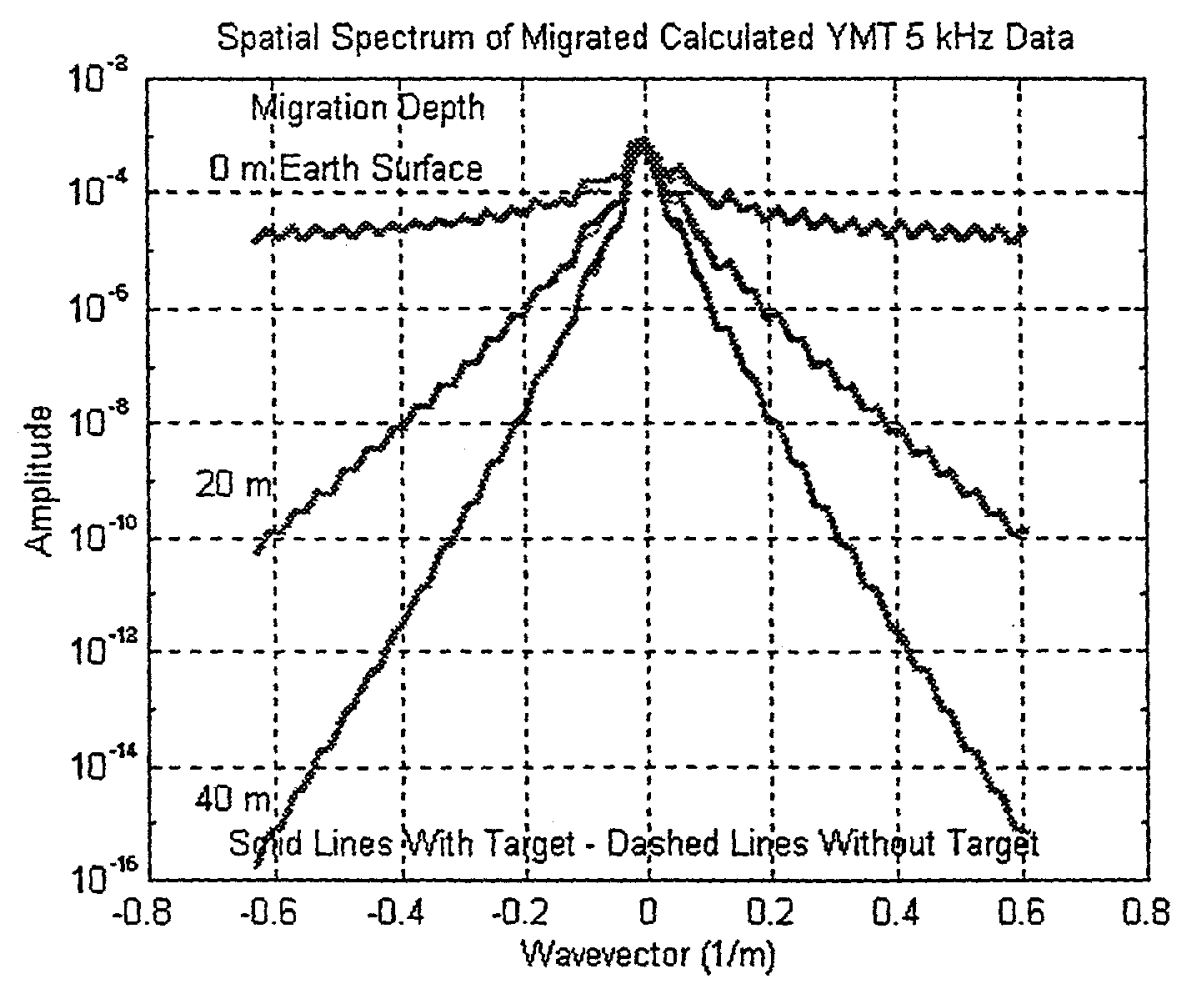

Fig. 22 Wavevector amplitude of migrated calculated $5 \mathrm{kHz}$ YMT data. 


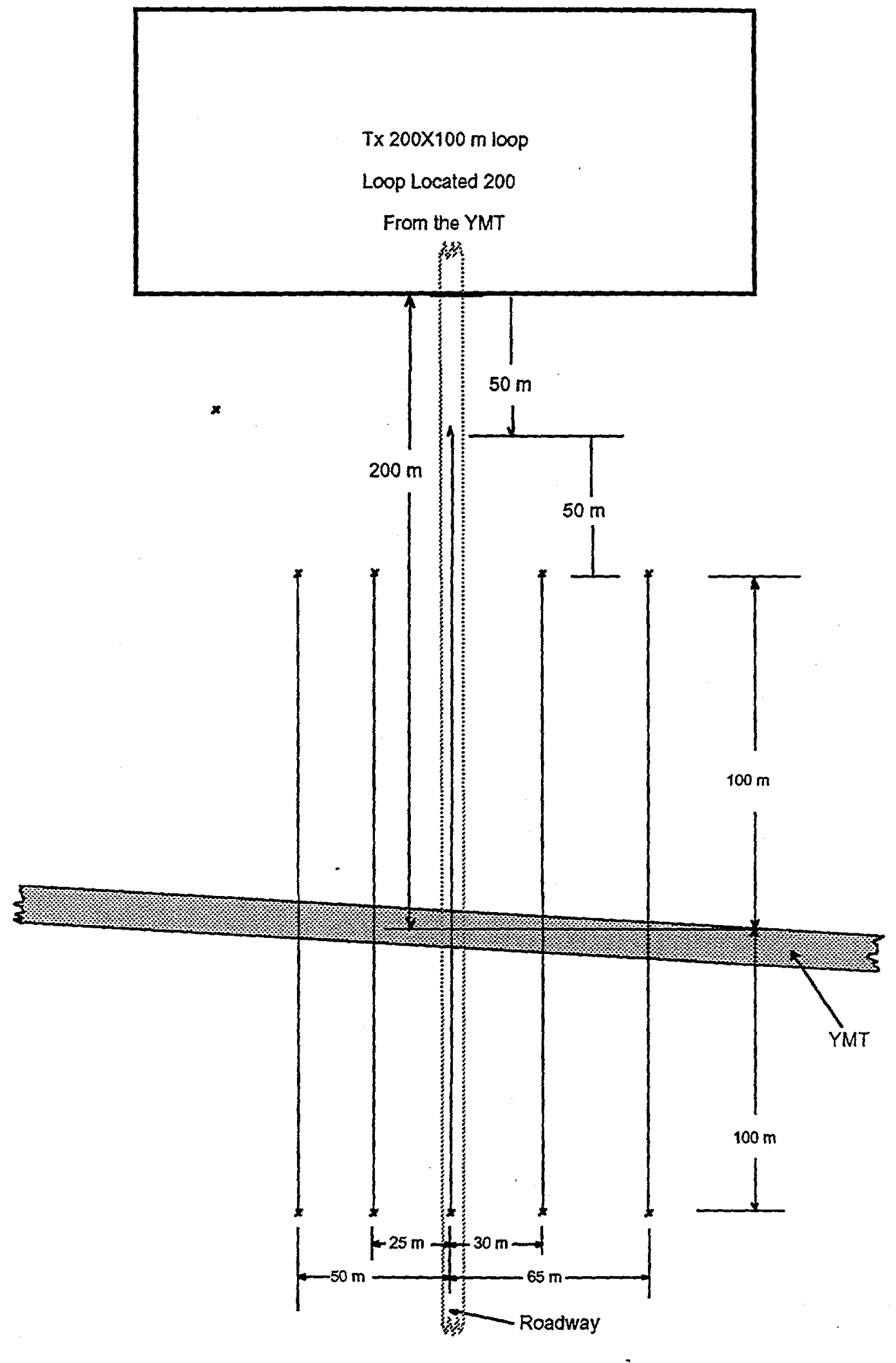

Survey Lines Parallel to the Roadway

Fig. 23 Yucca Mountain Tunnel survey. 


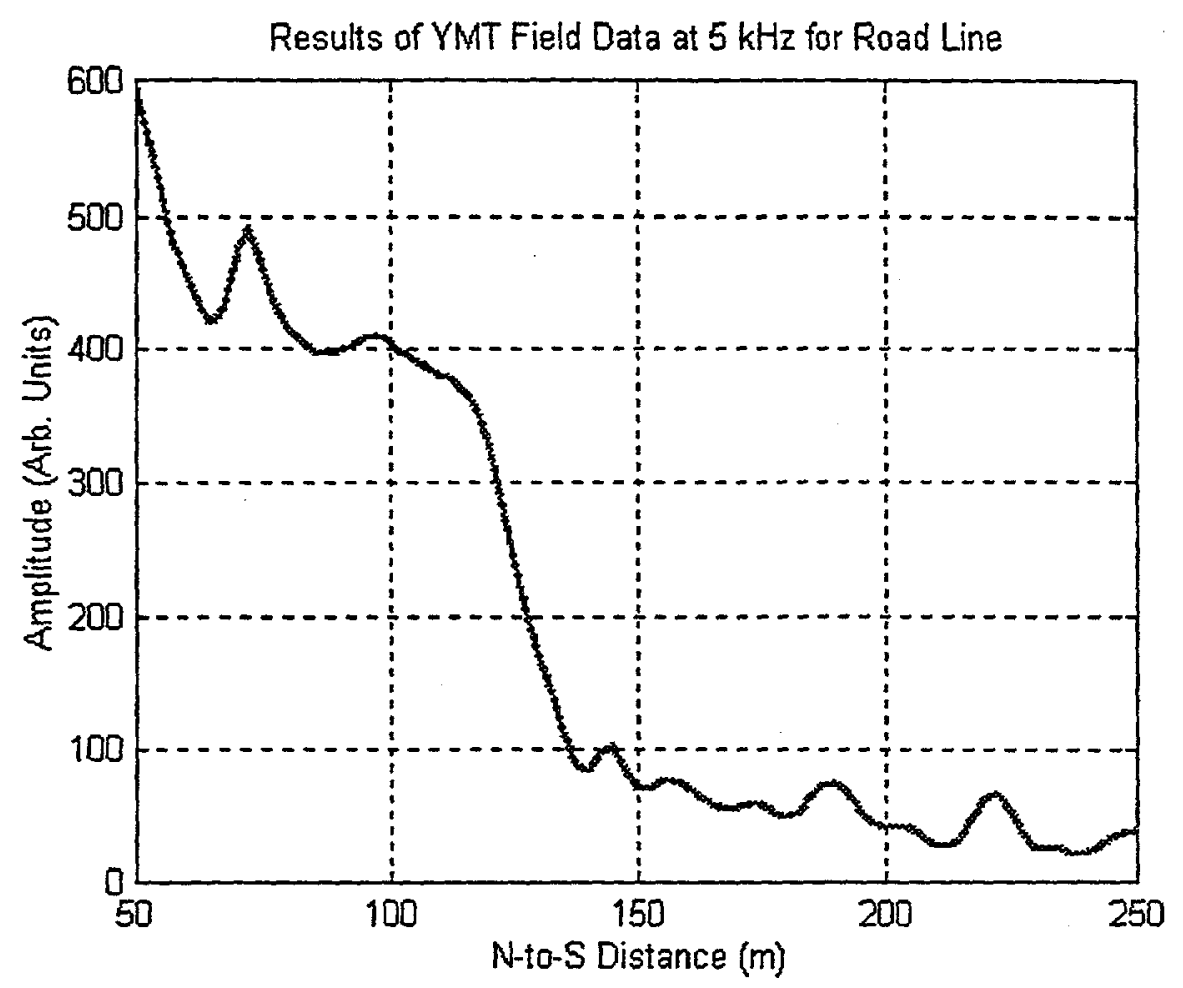

Fig. 24 Amplitude results for YMT field data at $5 \mathrm{kHz}$ along the Road Line.

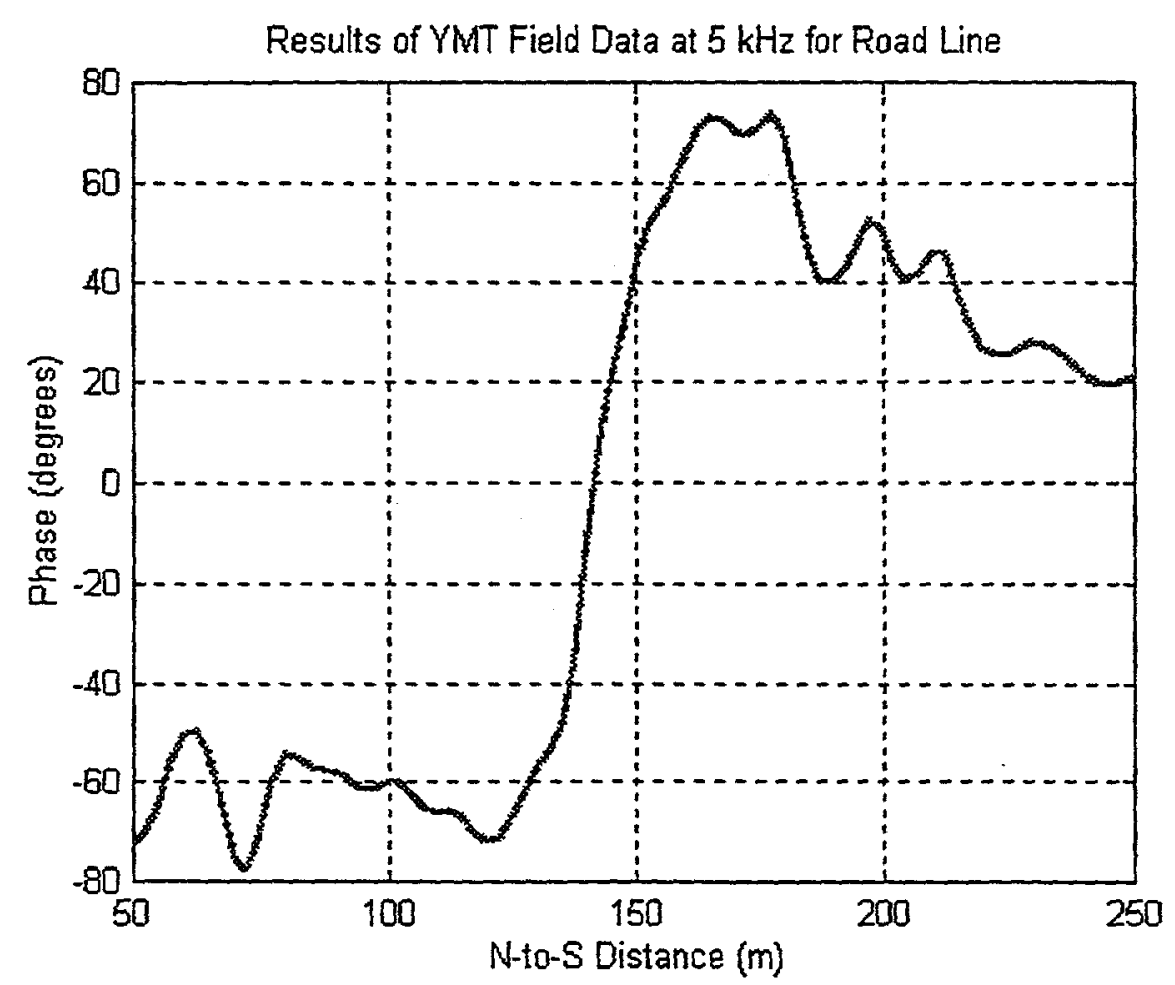

Fig. 25 Phase results for field YMT data at $5 \mathrm{kHz}$ for the Road Line. 


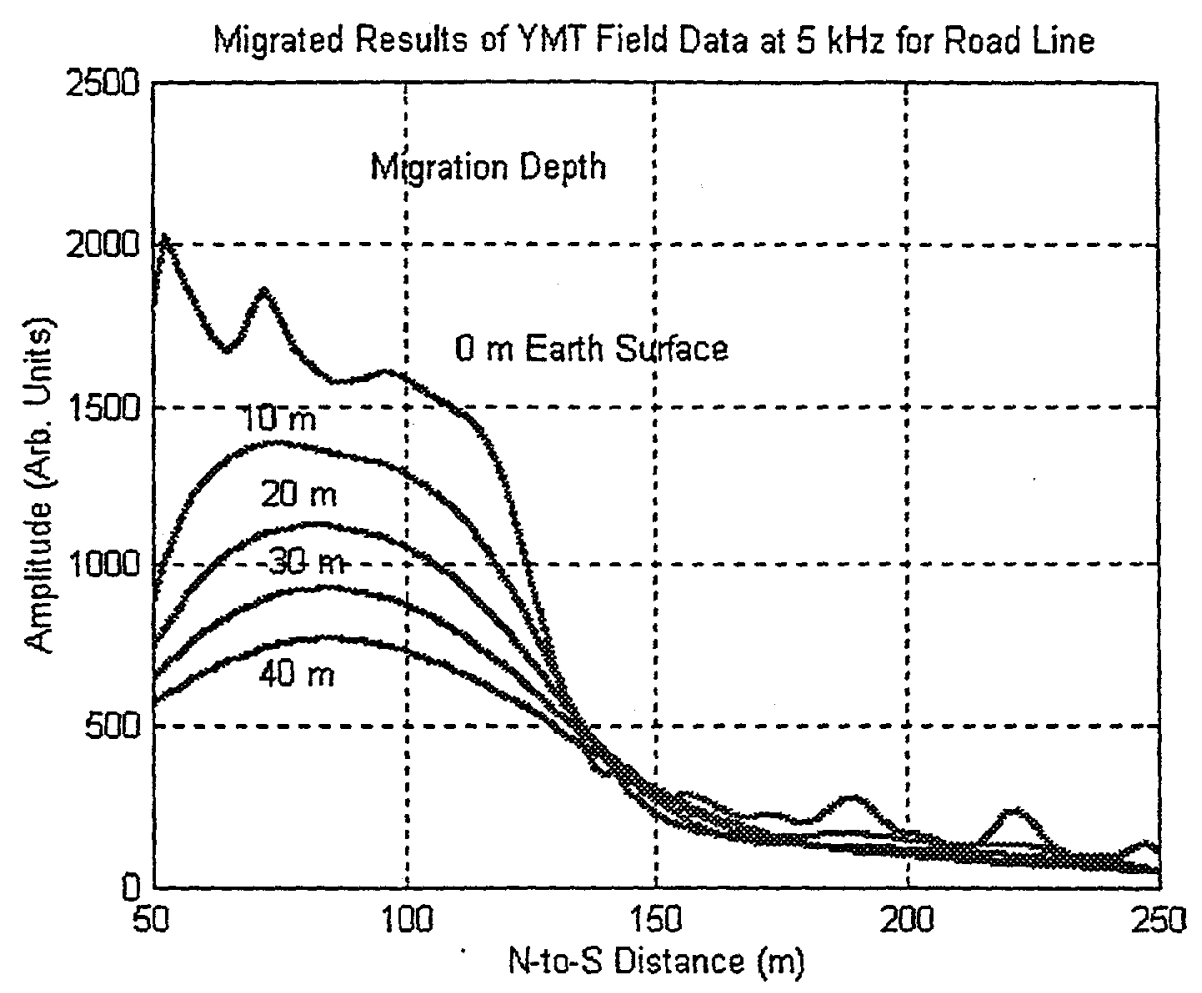

Fig. 26 Amplitude results for migrated $5 \mathrm{kHz}$ YMT field data for Road Line.

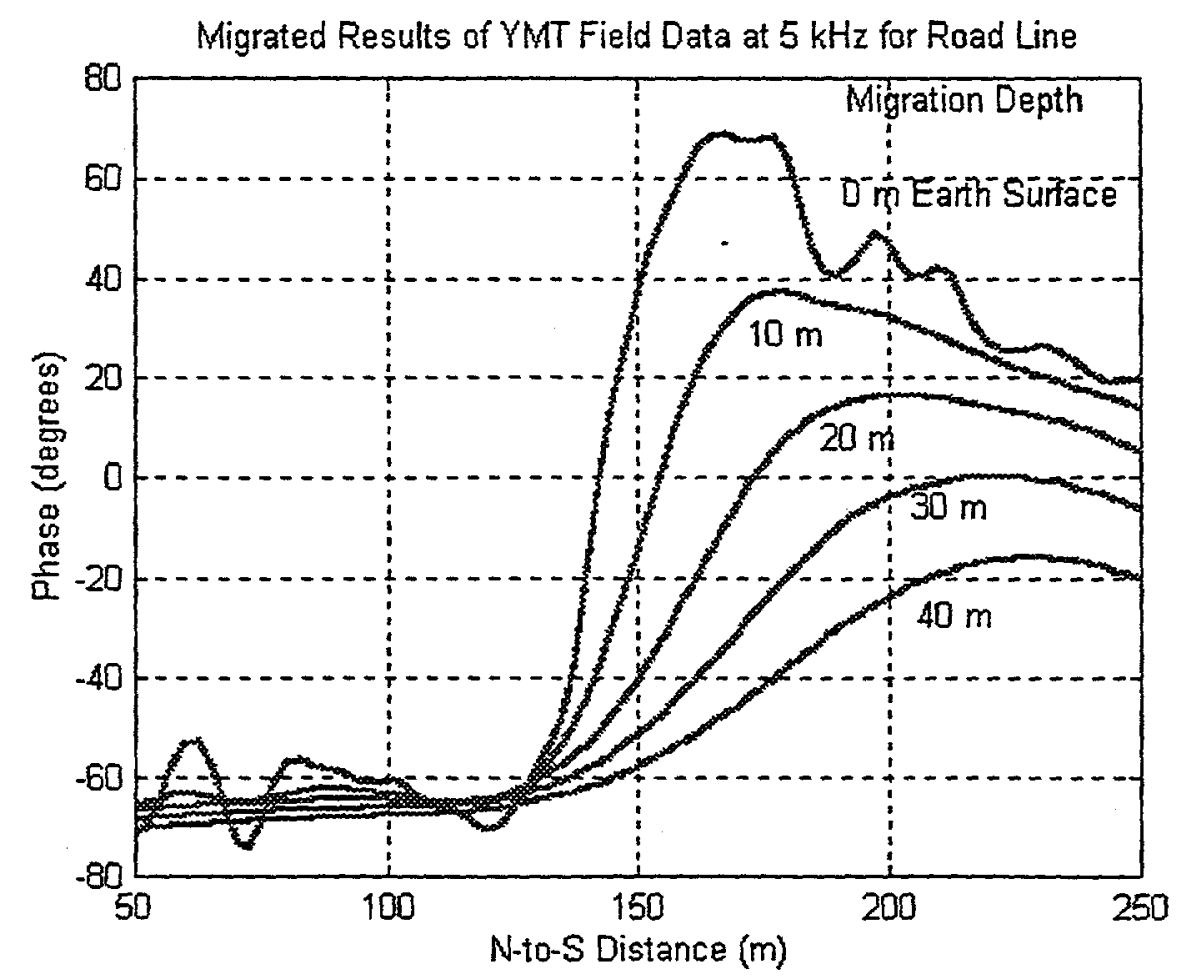

Fig. 27 Phase of migrated results for $5 \mathrm{kHz}$ YMT field data for Road Linè. 
Difference of Migrated Results for YMT $5 \mathrm{kHz}$ for Road Line Data

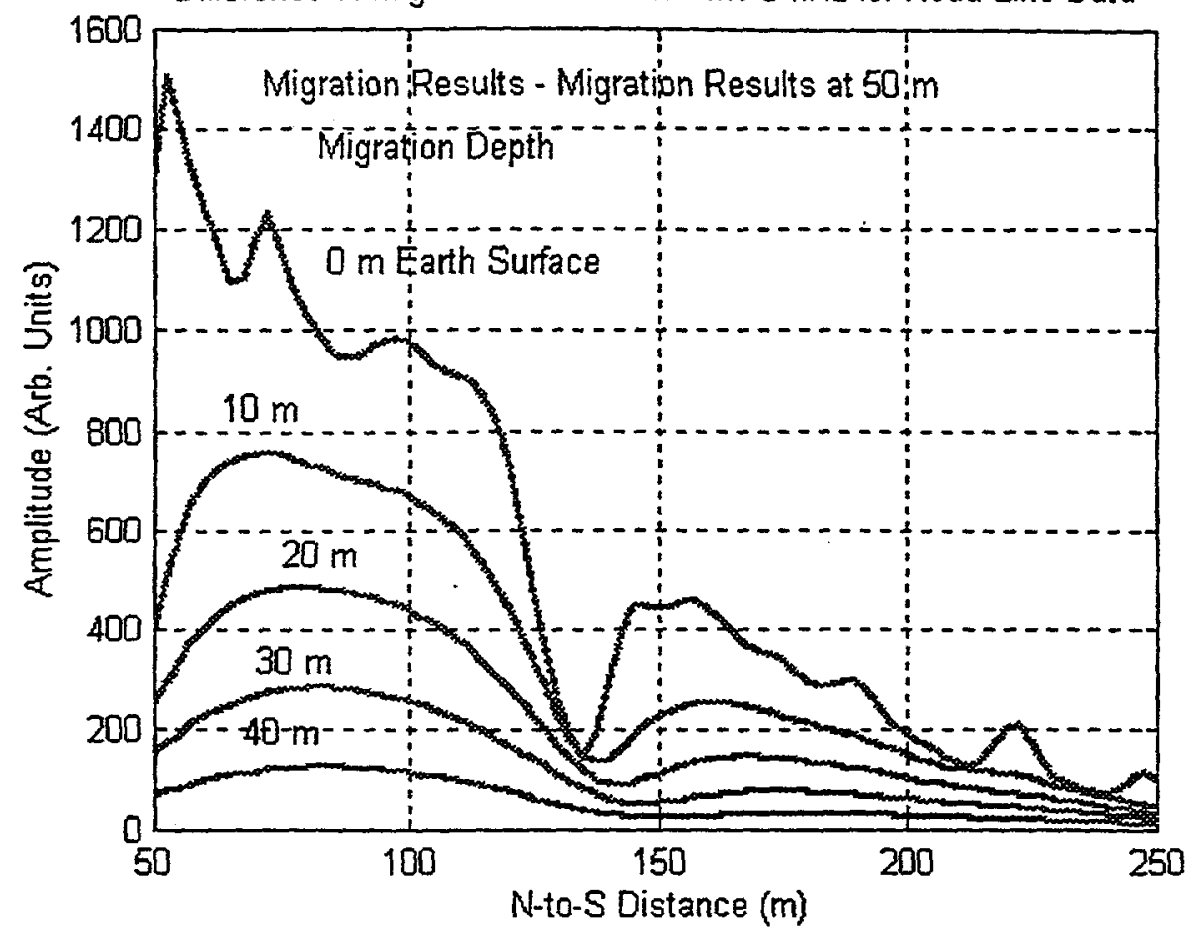

Fig. 28 Amplitude of the difference of migrated data at the depths shown minus the migrated data at $50 \mathrm{~m}$ deep.

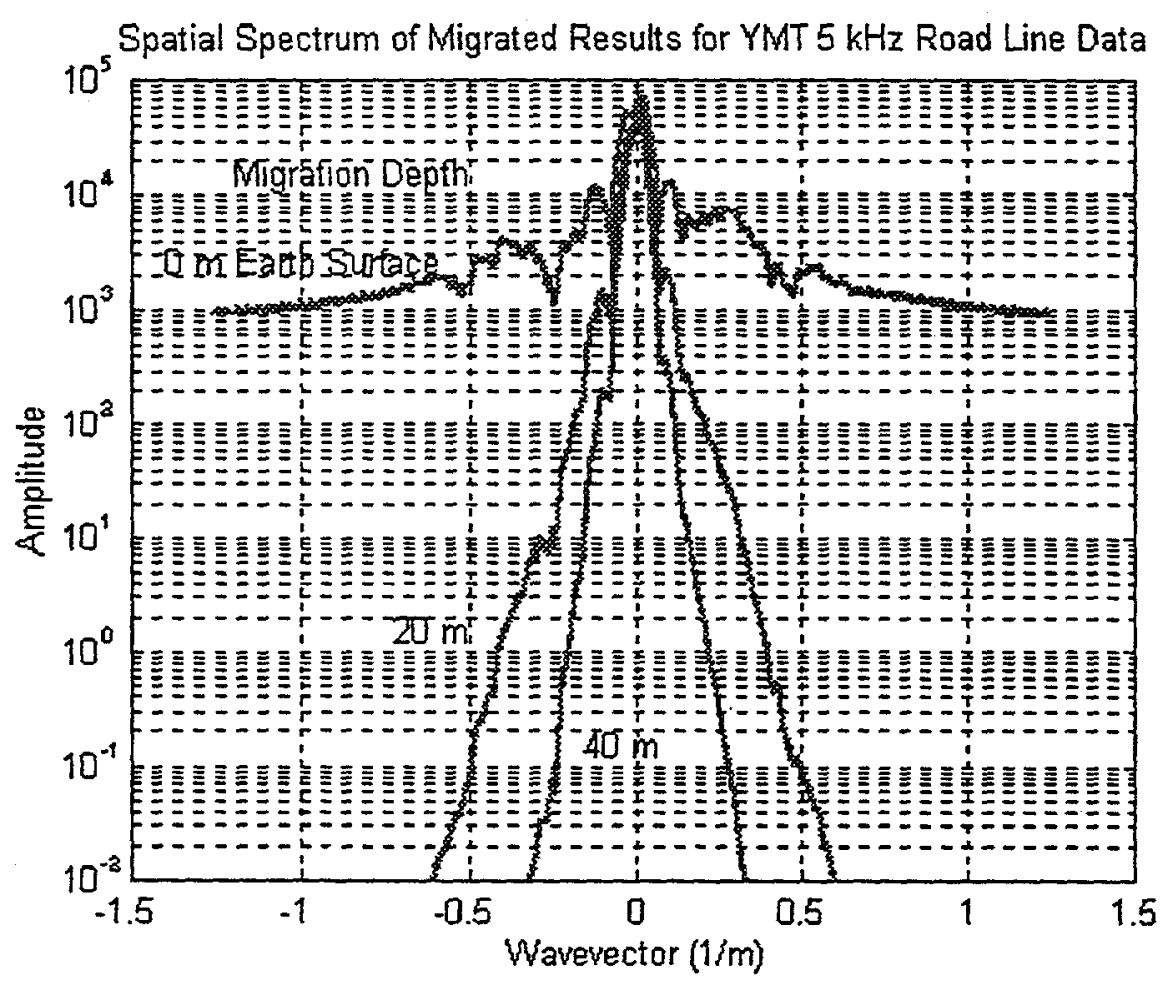

Fig. 29 Spatial spectrum of migrated $5 \mathrm{kHz}$ YMT Road Line data. 

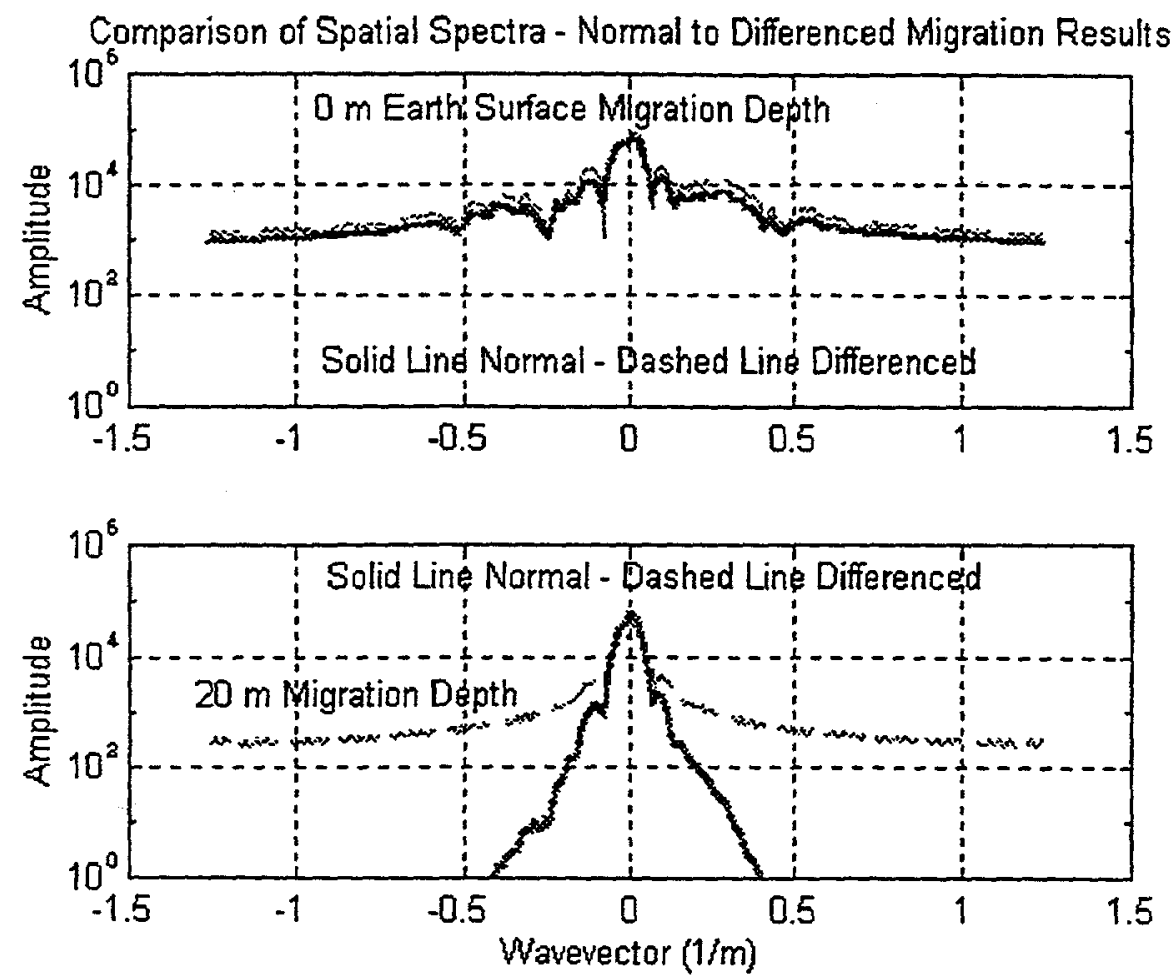

Fig. 30 Spatial spectrum of the comparison of normal migrated to differenced migrated 5 kHz YMT Road Line data. Shown are the spectra for the migrated depths.

3-D Amplitude Surface of YMT $5 \mathrm{kHz}$ Field Data

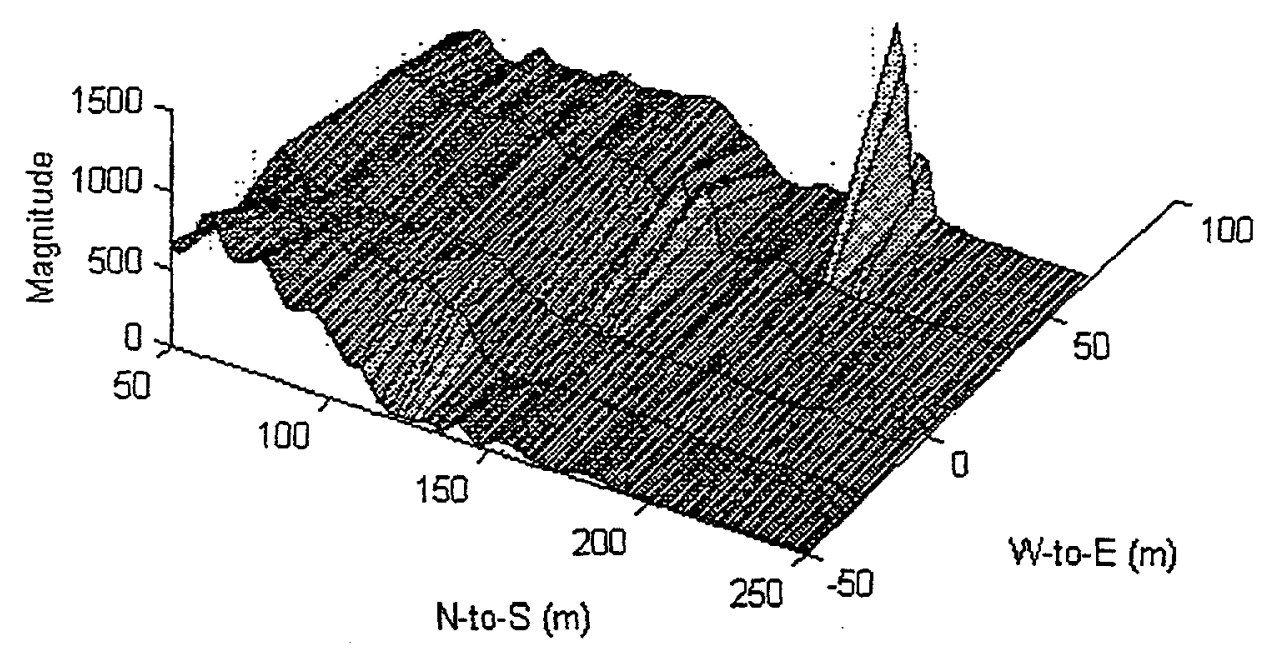

Fig. 31 3-D Amplitude surface of the YMT $5 \mathrm{kHz}$ field data. 


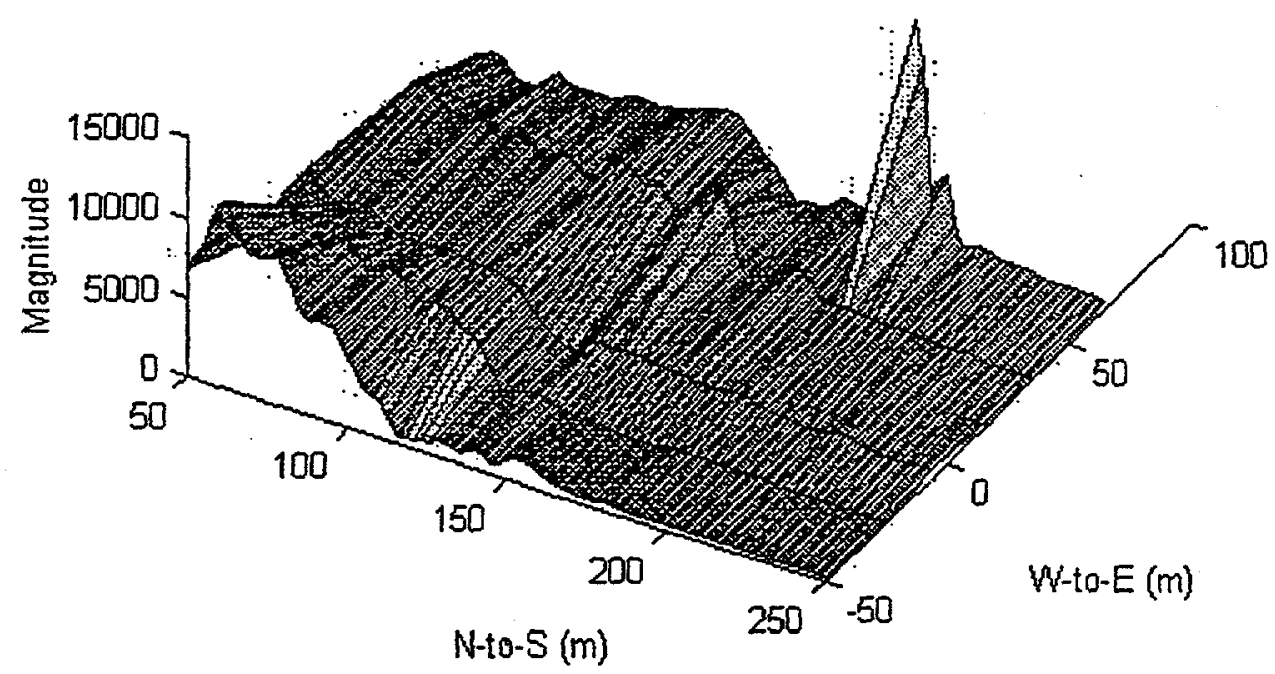

Fig. 32 3-D Amplitude surface of the YMT $5 \mathrm{kHz}$ field data migrated down to the earth's surface. Shown are the data at the surface minus the data migrated to $50 \mathrm{~m}$.

3-D Amplitude Surface of YMT $5 \mathrm{kHz}$ Field Data Migrated to Depth $20 \mathrm{~m}$

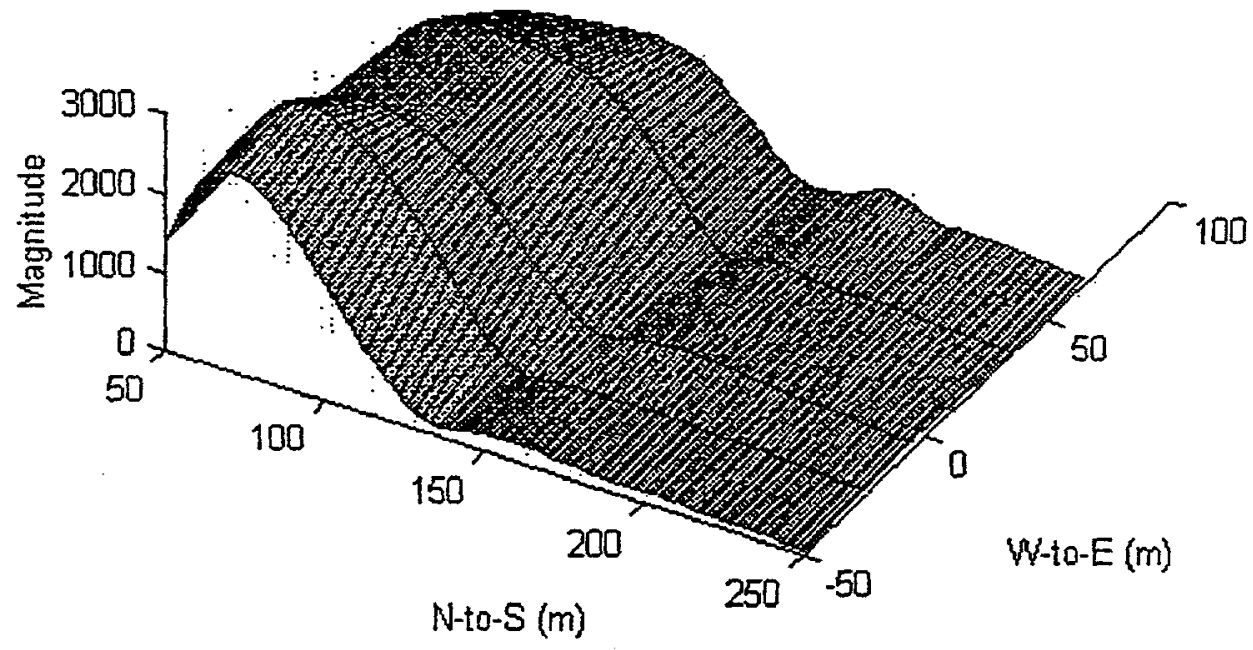

Fig. 33 3-D Amplitude surface of the YMT $5 \mathrm{kHz}$ field data migrated down to a depth of $20 \mathrm{~m}$. Shown are the data at the surface minus the data migrated to $50 \mathrm{~m}$. 
3-D Amplitude Surface of YMT $5 \mathrm{kHz}$ Field Data Migrated to Depth $30 \mathrm{~m}$

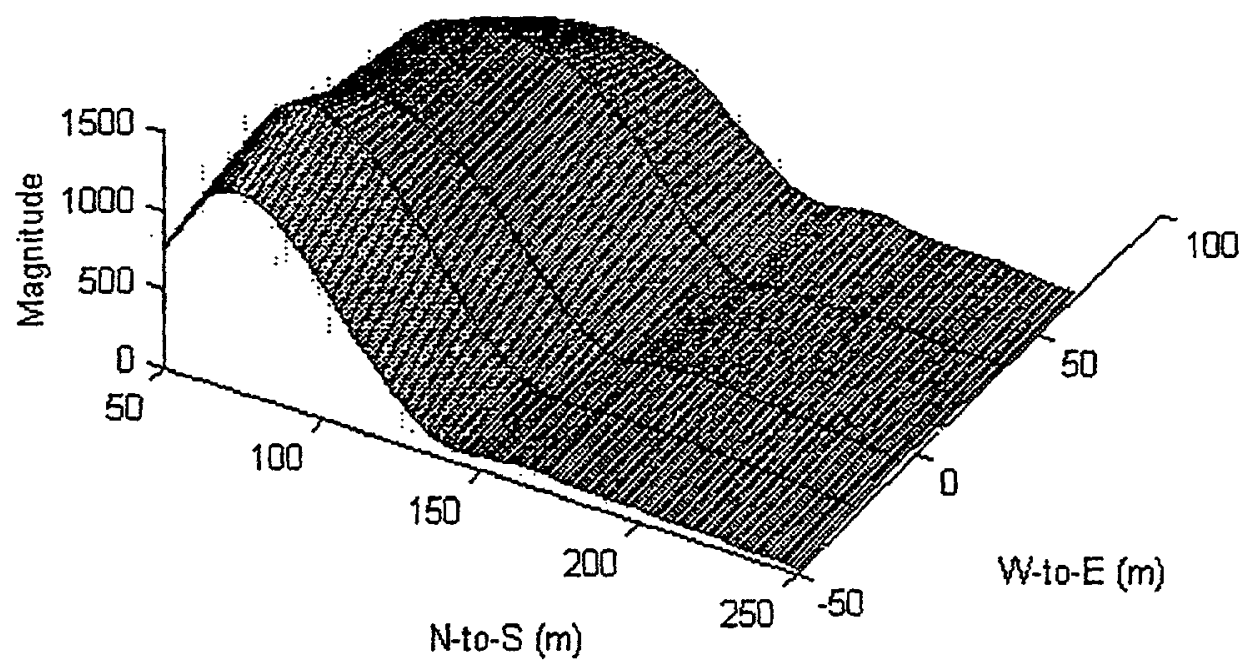

Fig. 34 3-D Amplitude surface of the YMT $5 \mathrm{kHz}$ field data migrated down to a depth of $30 \mathrm{~m}$. Shown are the data at the surface minus the data migrated to $50 \mathrm{~m}$.

3-D Amplitude Surface of YMT $5 \mathrm{kHz}$ Field Data Migrated to Depth $40 \mathrm{~m}$

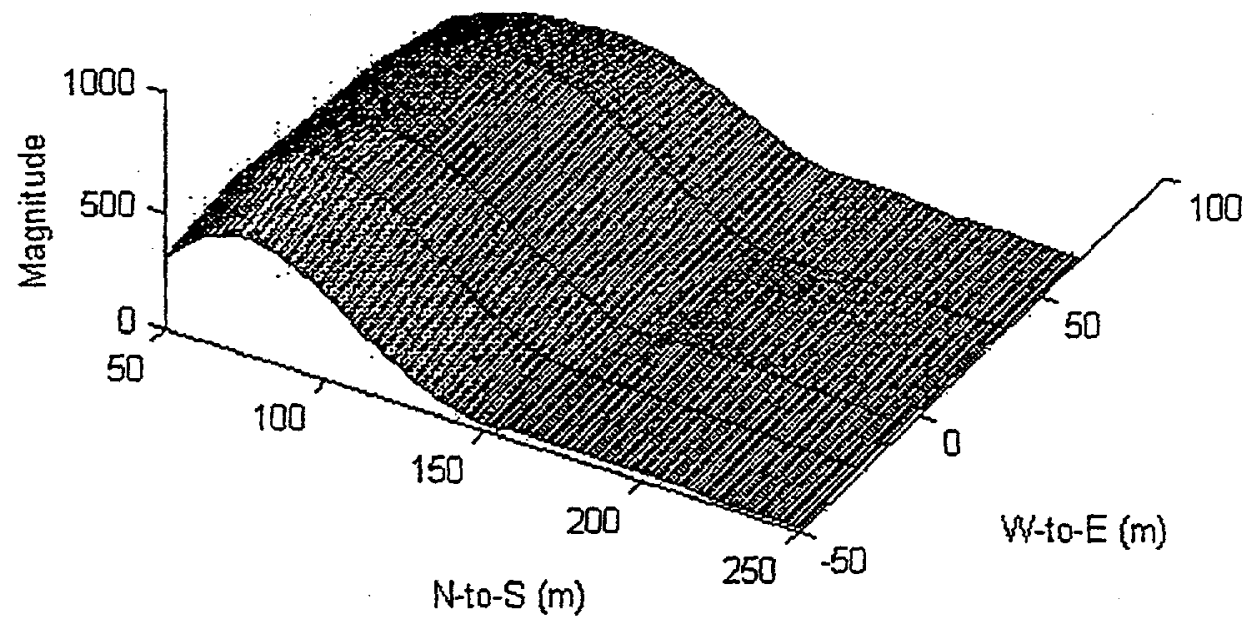

Fig. 35 3-D Amplitude surface of the YMT $5 \mathrm{kHz}$ field data migrated down to a depth of $40 \mathrm{~m}$. Shown are the data at the surface minus the data migrated to $50 \mathrm{~m}$. 
Distribution:

25 Karl Veith

Office of Research and Development

$\mathrm{NN}-20, \mathrm{GA}-300$

1000 Independence Ave. SW

Washington, DC 20585

5 Lawrence Stolarczyk

Raton Technology Research, Inc.

848 Clayton Highway

Raton, NM 87740-0428

$10533 \quad$ B. C. Brock, 2343

$10842 \quad$ C. M. Hart, 2500

$10843 \quad$ K. T. Stalker, 2524

10859 S. M. Guiterrez, 2527

10859 R. M. Huelskamp, 2527

10859 P. D. Rockett, 2527

50899 Technical Library, 4414

$10567 \quad$ R. D. Horton, 5318

10459 J. M. Taylor, 5335

$15 \quad 0877 \quad$ D. H. Cress, 5933

10573 H. M. Poteet, 5933

$250705 \quad$ L. C. Bartel, 6116

10705 T. W. H. Caffey, 6116

10750 M. C. Walck, 6116

10750 D. L. Alumbaugh, 6116

10750 G. A. Newman, 6116

19018 Central Technical Files, 8940-2

20619 Review and Approval Desk, 12630

For DOE/OSTI 